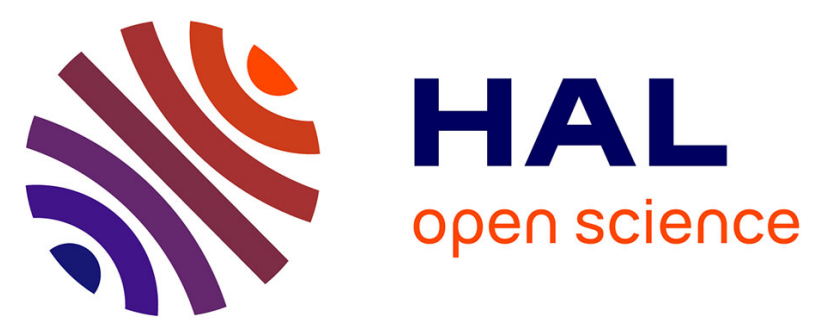

\title{
Reconciling two alternative mechanisms behind bi-decadal variability in the North Atlantic
}

Pablo Ortega, Juliette Mignot, Didier Swingedouw, Florian Sévellec, Éric Guilyardi

\section{To cite this version:}

Pablo Ortega, Juliette Mignot, Didier Swingedouw, Florian Sévellec, Éric Guilyardi. Reconciling two alternative mechanisms behind bi-decadal variability in the North Atlantic. Progress in Oceanography, 2015, 137 (Part A), pp.237-249. 10.1016/j.pocean.2015.06.009 . hal-01176201

\section{HAL Id: hal-01176201 \\ https://hal.sorbonne-universite.fr/hal-01176201}

Submitted on 16 Jul 2015

HAL is a multi-disciplinary open access archive for the deposit and dissemination of scientific research documents, whether they are published or not. The documents may come from teaching and research institutions in France or abroad, or from public or private research centers.
L'archive ouverte pluridisciplinaire HAL, est destinée au dépôt et à la diffusion de documents scientifiques de niveau recherche, publiés ou non, émanant des établissements d'enseignement et de recherche français ou étrangers, des laboratoires publics ou privés. 


\section{Reconciling two alternative mechanisms behind}

2 bi-decadal variability in the North Atlantic

3

4 Pablo Ortega (1), Juliette Mignot (1,2), Didier Swingedouw (3), Florian Sévellec (4), Eric

5 Guilyardi $(1,5)$

$6{ }^{1}$ LOCEAN Laboratory-IPSL, Sorbonne Universités (UPMC, Univ Paris 06)-CNRS-IRD-MNHN,

74 place Jussieu, F-75005 Paris, France

$8{ }^{2}$ Climate and Environmental Physics and Oeschger Centre for Climate Change Research,

9 University of Bern, Switzerland

$10{ }^{3}$ EPOC, Université Bordeaux, Bordeaux, France

$11{ }^{4}$ Ocean and Earth Science, National Oceanography Centre Southampton,University of

12 Southampton, Southampton, UK

13 5NCAS-Climate, University of Reading, UK

14 Corresponding author:

15 Pablo Ortega E-mail: pablo.ortega@locean-ipsl.upmc.fr

MANUSCRIPT ACCEPTED IN PROGRESS IN OCEANOGRAPHY

18 Abstract:

Understanding the preferential timescales of variability in the North Atlantic, usually associated with the Atlantic meridional overturning circulation (AMOC), is essential for the prospects for decadal prediction. However, the wide variety of mechanisms proposed from the analysis of climate simulations, potentially dependent on the models themselves, has stimulated the debate of which processes take place in reality. One mechanism receiving increasing attention, identified both in idealised models and observations, is a westward propagation of subsurface buoyancy anomalies that impact the AMOC through a basin-scale intensification of the zonal density gradient, enhancing the northward transport via thermal wind balance. In this study, we revisit a control simulation from the Institut Pierre-Simon Laplace Coupled Model 5A (IPSL-CM5A), characterised by a strong AMOC periodicity at 20 years, previously explained by an 
31 upper ocean-atmosphere-sea ice coupled mode driving convection activity south of

32 Iceland. Our study shows that this mechanism interacts constructively with the basin

33 mode propagation in the subsurface. This constructive feedback may explain why bi-

34 decadal variability is so intense in this coupled model as compared to others.

\section{1. Introduction}

36 A growing body of studies reports dominant variability in the North Atlantic at the 20-

3730 and 50-70 year time scales, in models (Delworth et al., 1993; Timmermann et al.,

38 1998; Cheng et al., 2004; Dong \& Sutton, 2005; Danabasoglu, 2008; Ortega et al., 2012;

39 Escudier et al., 2013), as well as in observational (Schlesinger \& Ramankutty, 1994;

40 Venegas \& Mysak, 2000; Rayner et al., 2003; Frankcombe et al., 2010) and proxy sources

41 (Gray et al., 2004; Sicre et al., 2008; Chylek et al., 2011; Cronin et al., 2014). Nevertheless,

42 to date, no consistent explanation succeeds in providing a common coherent

43 mechanism to any of these two preferential frequency bands.

44 One of the most challenging issues for decadal prediction is the identification of 45 mechanisms with important impacts on climate. The AMOC is a key player for North 46 Atlantic multidecadal variability; however, its ultimate drivers are not yet completely

47 understood. Since the pioneering work of Delworth et al. (1993), characterizing an 48 AMOC 50-year damped oscillation in an early version of the atmosphere-ocean coupled 49 model of the Geophysical Fluid Dynamics Laboratory (GFDL), which resulted from an 50 interplay between North Atlantic deep convection and salinity advection from southern

51 latitudes, many other alternative mechanisms have been identified in other models.

52 Even if many studies still support a leading role of convection on AMOC variability, the

53 feedback processes and the time-scales involved are very diverse. Also, it is not always

54 clear whether and how the AMOC adjust to changes in deep convection and deep water

55 formation (Deshayes \& Frankignoul, 2005). 
56 A similar mechanism to the one described for the early version of the GFDL model has

57 been identified by Dong \& Sutton (2005) in the third Hadley Centre coupled Climate

58 Model (HadCM3), but operating at a shorter timescale: 25 years. Other studies

59 (Danabasoglu, 2008; Ortega et al., 2012) using respectively the Community Climate

60 System Model version 3 (CCSM3) and the coupled model European Centre Hamburg 4-

61 Hamburg Ocean Primitive Equation-G (ECHO-G) link Labrador deep water formation

62 and the North Atlantic Oscillation with preferential variability at 20 years. Both support

63 a crucial role of the atmosphere through associated surface fluxes and wind-stress curl

64 forcing. Kwon and Frankignoul (2014) have revisited the former CCSM3 simulation and

65 propose an alternative ocean-only mode instead, where bi-decadal variability results

66 from an interaction between the North Atlantic Current (NAC) and the equatorward

67 deep return flow. Feedback mechanisms with the Intertropical Convergence Zone

68 (ITCZ) can also produce centennial AMOC modulations, as observed first by Vellinga

69 and Wu (2004) in HadCM3, and later on by Menary et al (2012) in other models. There

70 are also internal ocean mechanisms that relate AMOC variability at long timescales [up

71 to 80 years] to the export of freshwater anomalies from the Arctic into the Nordic

72 (Jungclaus et al., 2005) and Labrador Seas (Hawkins \& Sutton, 2007), respectively for

73 the European Centre Hamburg Model version 5-Max Planck Institute Ocean Model

74 (ECHAM5/MPI-OM) and HadCM3. More recently, Escudier et al. (2013) have shown that

75 the East Greenland Current (EGC) intensity is paramount to explain the phase reversal

76 of a bi-decadal ocean mode from the low-resolution version of the Institut Pierre-Simon

77 Laplace Coupled Model 5A (hereafter IPSL-CM5A), involving surface salinity advection

78 by the subpolar gyre as a driver of convective activity south of Iceland and subsequently

79 of the AMOC. All these mechanisms are difficult to reconcile, as they might be model-

80 dependent. One common aspect identified in several models is the modulation of the 
81 AMOC and NAC strength by changes in upper ocean density anomalies at the western

82 margin of the basin, an important region for the thermal wind relation (Tulloch \&

83 Marshall, 2012). The source region of these anomalies can however vary from one

84 model to another, depending, for example, on the location of the main regions of 85 convection.

86 One multidecadal mechanism consistently identified in idealized ocean models (e.g.

87 Colin de Verdière \& Huck, 1999; Huck et al., 1999; te Raa \& Dijkstra, 2002) is related to

88 the westward propagation of subsurface temperature anomalies across the North

89 Atlantic basin. It will be hereafter referred to as subsurface basin mode, to acknowledge

90 the importance of closed east and west boundaries to select the zonal wavenumbers,

91 which set the timescale of the oscillation (Sévellec and Huck, 2015). Its link with the

92 AMOC is explained by a thermal-wind driven interplay between the zonal and

93 meridional overturning circulations (te Raa \& Dijkstra, 2002). This mechanism is also

94 referred to as "thermal Rossby mode", because temperature anomalies propagate

95 westwards across the mean temperature gradient, in the same way that Rossby waves

96 do across the background potential vorticity gradient field. There exist evidence of a

97 similar westward propagation in North Atlantic observations of sea-level height (e.g.

98 Tulloch et al., 2009; Vianna \& Menezes, 2013), subsurface (Frankcombe et al., 2008), and

99 sea surface temperature (Feng \& Dijkstra, 2014), with comparable basin-crossing times

100 as for the subsurface basin mode. Despite this consistency between observations,

101 modeling and theory, it is still under debate whether this interdecadal AMOC variability

102 is excited by the atmosphere or maintained by pure ocean dynamics. Whereas Colin de

103 Verdière and Huck (1999) and Sévellec and Huck (2015) suggest that it can be internally

104 forced by large-scale baroclinic instabilities, Killworth and Blundell (2007) and Sévellec

105 et al (2009) advocate for the need of an external energy source, either a local wind 
106 forcing or a buoyancy exchange (e.g. heat or freshwater fluxes). Recently, Sévellec and

107 Fedorov (2013) have demonstrated that this oscillation appears as the least damped

108 multidecadal oscillatory mode in OPA (Océan PArallélisé), the oceanic component of the

109 IPSL-CM5A model. In their study, the AMOC exhibits a peak of preferential variability at

11020 years. The damped nature of this mode could point to a necessary role of the

111 atmosphere to sustain the AMOC oscillation, although this feature could be model

112 dependent. It remains therefore unclear whether this potentially damped internal

113 ocean mode will be present when the ocean model OPA is coupled to an atmospheric

114 model. Another question is whether this mode is compatible with the convection-driven

115 AMOC mechanisms described above.

116 These two intriguing questions can be addressed within the IPSL-CM5A model. Here we

117 revisit the same coupled control simulation analysed in Escudier et al. (2013) and

118 demonstrate that their upper ocean-atmosphere-sea ice coupled mechanism coexists

119 with a multidecadal subsurface basin mode like the one described in Sévellec and

120 Fedorov (2013) for the ocean component alone. Hence, new questions will be also

121 tackled: Are both modes developing independently, and interact constructively or

122 destructively over time? Otherwise, is one driving the other? Or are both coupled to

123 each other? We will show that both oscillations are intrinsically linked, as two different

124 expressions of a larger coupled mechanism.

125 The paper is organised as follows. The model and the coupled run are presented in

126 Section 2. This section also includes a detailed description of the two mechanisms

127 investigated. Section 3 assesses the presence of the subsurface basin mode in the 128 coupled model, and Section 4 investigates the potential feedbacks between the two $a$

129 priori different modes. Conclusions and a discussion of implications are included in 130 section 5. 


\section{2. Model and theoretical basis}

$132 \quad 2.1$ The IPSL-CM5A model

133 The analysis is based on a 1000-year long control preindustrial run with the IPSL-CM5A

134 model, performed within the framework of the fifth Coupled Model Intercomparison

135 Project (CMIP5). It uses the LMDZ5A (Laboratoire de Météorologie Dynamique-Zoom 136 version 5A) atmospheric circulation model (Hourdin et al. 2013), under a regular $96 \mathrm{x}$ 13796 point horizontal grid (i.e. $3.75^{\circ} \times 1.875^{\circ}$ ) with 39 levels in the vertical. The oceanic 138 component is the Nucleus for European Modelling of the Ocean (NEMO) version 3.2 139 (Madec, 2008). It includes the OPA9 ocean circulation model, coupled with the Louvain140 la-Neuve (LIM2) sea-ice model version 2 (Fichefet \& Maqueda, 1997) and

141 the biogeochemical module PISCES (for Pelagic Interaction Scheme for Carbon \&

142 Ecosystem Studies; Aumont \& Bopp, 2006). The ocean component includes 31 vertical

143 levels, 15 of them in the upper $150 \mathrm{~m}$ and has an irregular horizontal grid of $182 \times 149$

144 points, characterized by a nominal resolution of $2^{\circ}$ with an enhancement over the Arctic,

145 the subpolar North Atlantic and near the Equator. Further details on the model 146 configuration, its different components and the boundary conditions imposed to run the

147 control simulation can be found in Dufresne et al. (2013) and references therein. Other

148 studies describing the components and various different aspects of the model

149 performance are compiled in a special issue of Climate Dynamics

150 (http://link.springer.com/journal/382/40/9/). In particular, the performance of the

151 oceanic component in the coupled model configuration is assessed in Mignot et al.

152 (2013).

$153 \quad 2.2$ The upper ocean-atmosphere-sea ice coupled mode

154 In a first analysis of the control IPSL-CM5A simulation, Escudier et al. (2013) identified

155 a strong 20-year periodicity in several key variables across the North Atlantic basin. 
156 This common variability is explained through a coupled atmosphere-ocean mode

157 mainly acting in the upper ocean (Figure 1). The 20-year cycle starts, for example, with

158 a deceleration of the EGC, which reduces the export of fresh and cold polar waters

159 through the Denmark Strait. This generates within 3 years anomalous warm and salty 160 upper waters in the Labrador Sea that are advected eastward by the subpolar gyre, and

161 reach, in 5 years time, a region of convection located South of Iceland, and 2 years after

162 the Nordic Seas. The region South of Iceland is the major area for deep convection in the

163 model, but its role is less important in the real world (Marshall and Schott, 1999). This

164 model bias should be kept in mind when assessing the realism of this mode. In the

165 Nordic Seas, the warm temperature anomalies contribute to reduce the sea-ice extent,

166 and produce a cyclonic atmospheric circulation response, leading to an intensification

167 of the Ekman transport over the Denmark Strait, and ultimately of the EGC strength.

168 This atmospheric link, although rather weak, provides the necessary feedback for the

169 phase reversal 10 years after the initial EGC weakening. The EGC phase reversal is also

170 fostered by a reduction in the sea ice cover over the Denmark Strait region, which

171 increases the momentum exchange between the atmosphere and the ocean. The second

172 part of the cycle evolves similarly, this time with fresh and cold surface waters from the

173 Arctic being advected along the subpolar gyre, and giving rise 7 years later to positive

174 sea ice extent and negative SLP anomalies in the Nordic Seas. The AMOC does not seem

175 to play an active role in this mechanism. Nevertheless, it does respond passively, with 8-

1769 years lag, to changes in deep convection in the region South of Iceland. The reasons

177 for this particular lagged response were not addressed in the original study of Escudier

178 et al (2013) and are further explored in the present study.

179 Due to the predominant role of surface variables in this bi-decadal mode, the IPSL-

180 CM5A model has a great potential for AMOC initialization and decadal prediction. 
181 Indeed, two perfect model analyses by Persechino et al. (2013) and Servonnat et al.

182 (2015) have respectively shown that, in the model, the AMOC has an average potential

183 predictability of 8 years and can be successfully recovered, by applying a nudging to sea

184 surface temperature and salinity fields, that is able to initialize its major precursors (e.g.

185 EGC, convection South of Iceland). Likewise, Swingedouw et al. (2013) argued that this

186 advective surface mechanism may explain two of the observed Great Salinity Anomalies

187 occurring in the 1970s and 1990s (Belkin et al., 1998), which in the model follow an

188 excitation of this 20-year cycle by Mt Agung eruption.

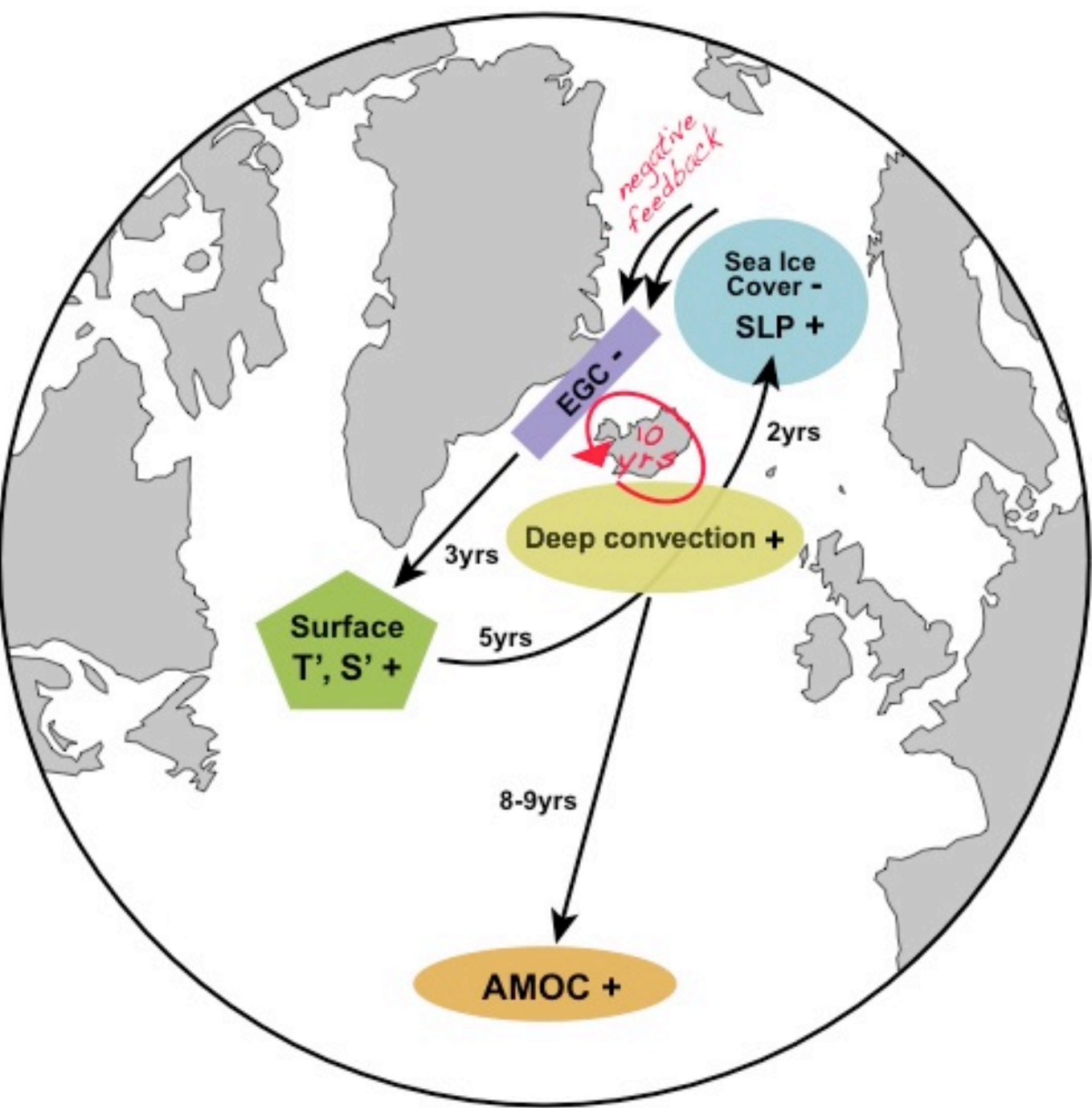

191 Figure 1: Schematic representation of the advective mechanism, modified from Figure 13 in Escudier et al. (2013). Estimated time-lags are indicated along the arrows. The corresponding sign of the anomalies appears next to each variable. 
196 This multidecadal oscillatory mechanism has been identified in several idealized models

197 and theoretical studies (e.g. Colin de Verdière \& Huck, 1999; Huck et al. 1999; Te Raa \&

198 Dijkstra, 2002; Sévellec \& Huck, 2015), as well as in the linearized version of the ocean

199 component of IPSL-CM5A, as described in Sévellec and Fedorov (2013). It is

200 characterised by a large-scale westward propagation of subsurface density anomalies,

201 typical of large-scale baroclinic Rossby waves (Colin de Verdière \& Huck, 1999). This

202 westward propagation can occur even under the presence of a dominant eastward

203 mean flow, due to the contribution of two additional terms that oppose the mean zonal

204 advection: the geostrophic self-advection and the $\beta$-effect. Geostrophic self-advection,

205 initially characterised within the paradigm of the non-Doppler shift effect (e.g. Rossby,

206 1939; Held, 1983; Killworth et al., 1997), is triggered by a local density perturbation

207 (either thermal or haline) embedded along a mean meridional density gradient

208 (normally increasing northward). For instance, positive local density anomalies

209 produce a geostrophic cyclonic response, bringing denser waters from the south to its

210 western flank, and lighter waters from the north to its eastern flank, thus leading to an

211 effective propagation to the west. Note that negative density anomalies also move

212 westward, because they induce an anticyclonic response instead. The other term, the $\beta$ -

213 effect, is typical of long non-dispersive baroclinic Rossby waves. It works similarly to

214 self-advection, but relies on the variation of the Coriolis parameter with latitude

215 (instead of the isopycnal depth). In the Northern Hemisphere, the $\beta$-effect is always

216 positive and thereby contributes to a westward propagation. The combination of the

217 mean zonal flow, the geostrophic self-advection and the $\beta$-effect determines the full

218 speed of the propagation (Sévellec and Fedorov, 2013).

219 The multidecadal oscillatory mode can be described following four major phases (two

220 of them shown in Figure 2). In Phase I, a large-scale positive density anomaly appears in 
221 the middle of the basin in the North Atlantic, and propagates westward consistently

222 with the self-advective mechanism. The propagation eventually leads to Phase II, in

223 which a zonal density gradient is established, with denser waters at the west and lighter

224 waters at the east of the Atlantic basin. This configuration strengthens the AMOC via

225 thermal wind balance. As a result of the associated enhanced downwelling in the North

226 Atlantic, the sign of the initial density anomalies is reversed a few years later. To

227 complete a full oscillation cycle, the two previous phases are followed by their two

228 corresponding opposite phases: negative density anomalies in the middle of the basin

229 propagating westward; and a weakening in the AMOC strength, caused by a reversal of

230 the zonal gradient in Phase II.

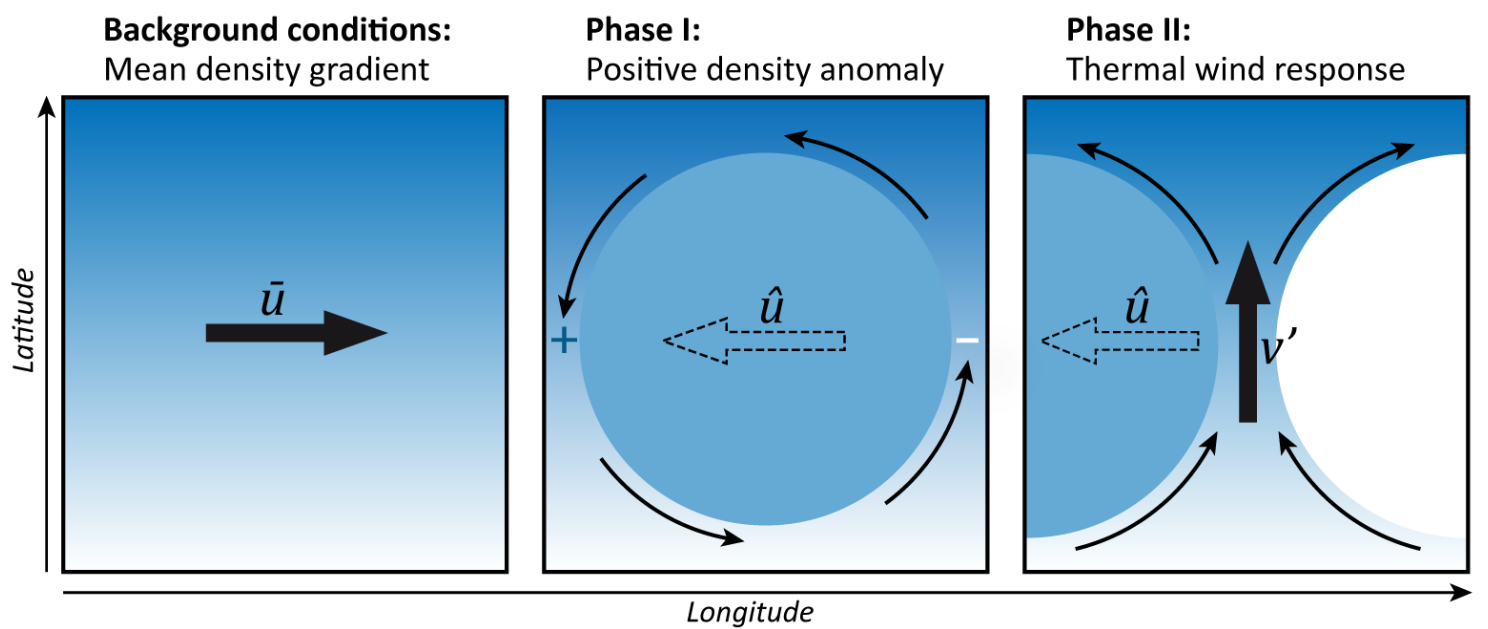

232 Figure 2: Schematic of the multidecadal oscillatory mode modified from Figure 4 of Sévellec and Fedorov

233 (2013). The background colour degradation represents the mean density distribution, with lighter waters

234 in white and heavier waters in blue. (Left) Background conditions correspond to a mean meridional

235 density gradient and an eastward mean zonal velocity $\bar{u}$. (Middle) In the first phase, positive density anomalies appear in the middle of the basin and generate a geostrophic cyclonic flow that induces a westward propagation. (Right) In phase II the original positive density anomaly has reached the western boundary, and negative anomalies have emerged in the east. This zonal density gradient intensifies the northward surface flow $v^{\prime}$ through thermal wind balance.

The basin mode is fundamentally linked to the existence of zonal boundaries, which

242 allow the reemergence of density anomalies at the eastern boundary, opposite in sign to

243 the anomalies reaching the western boundary. In OPA9, this reemergence is consistent

244 with a fast adjustment by Kelvin waves propagating southward along the western

245 boundary, through the equator, and subsequently northward along the eastern 
246 boundary (Sévellec and Fedorov, 2013), as previously described in Johnson and

247 Marshall (2002).

2492.4 Computation of the thermal wind transport.

250 As described above, the effect of the subsurface basin mode on the AMOC arises through

251 a modulation of the west-to-east density gradient, which triggers a meridional thermal

252 wind response. The northward thermal wind transport at a particular depth $z^{\prime}$ is

253 calculated using the following decomposition:

$$
\psi_{t w}(z)=\int_{x_{w}}^{x_{e}} d x \int_{-H}^{z}\left(\tilde{v}-v_{0}\right) d z^{\prime}
$$

255 where $x, \psi_{t w}, H, x_{e}, x_{w}, \tilde{v}$ and $v_{0}$ represent respectively the zonal coordinate, the

256 thermal-wind contribution to the meridional streamfunction, the total ocean depth, the

257 longitude of the eastern and western boundaries, the meridional velocity associated

258 with the zonal density gradient and a correction term introduced to guarantee mass

259 conservation without affecting the vertical shear.

260 The meridional velocity $\tilde{v}$ is calculated from the zonal density gradient as

261 follows:

$$
\tilde{v}(z)=\frac{g}{\rho_{0} f} \int_{-H}^{z} \frac{1}{L(z)}\left(\rho_{w}-\rho_{e}\right) d z^{\prime}
$$

263 where $z, g, \rho_{0}, \rho_{e}, \rho_{w}, f, L$ and $H$ are respectively the vertical coordinate, the 264 gravitational acceleration, a reference density, the density at the eastern and western

265 boundaries, the Coriolis parameter, the basin width, and the bottom of the ocean. Note

266 that, in essence, this decomposition is based on the geostrophic balance, the hydrostatic

267 approximation and mass conservation. It was derived and tested in depth in Hirschi and

268 Marotzke (2007), and has been used in an operational context for monitoring AMOC

269 variations within the RAPID array (Cunningham et al., 2007). 
2.5 Analysis and statistical assessment

271 Our study is mainly based on the statistical links of different indices among themselves

272 and also with other large-scale climate fields. All data correspond to annual means, and

273 anomalies are calculated with respect to the simulation long-term mean (i.e. 1000

274 years). Statistical significance of all the regression and correlation coefficients is

275 assessed following a two-tailed Student's $t$ test. Sample size is corrected by taking into

276 account the series autocorrelation, thus reducing the sample degrees of freedom to its

277 effective value (Bretherton et al., 1999).

\section{Characterizing the subsurface basin mode propagation in IPSL-CM5A}

279 The climatological maximum of the AMOC streamfunction is approximately $10 \mathrm{~Sv}$, well 280 below the range of observational estimates (Ganachaud \& Wunsch, 2000; Talley et al., 281 2003). This is probably caused by a misrepresentation of Labrador convection in the model, and an underestimation of the outflows from the Nordic Seas (Escudier et al., 283 2013).

284 To highlight the 20-year cycle in the AMOC, we define a meridional overturning index as 285 the maximum streamfunction value at $48^{\circ} \mathrm{N}(\mathrm{MOI}-48 \mathrm{~N})$ and remove the Ekman transport contribution. This is the latitude where the climatological means of both the full AMOC streamfunction and the thermal wind transport become maximum (Figure 3).

288 Note that the differences between both quantities in Figure 3 relate to the contribution 289 of the Ekman transport and to the approximations considered to derive Equation 1. 290 Despite the climatological differences, more important at depth, both quantities show 291 rather similar variability in the vicinity of the climatological maximum. The MOI-48N 292 and an equivalent index for the thermal wind transport are strongly correlated, with a correlation coefficient $r$ of 0.8 (significant at the 95\% confidence level). 

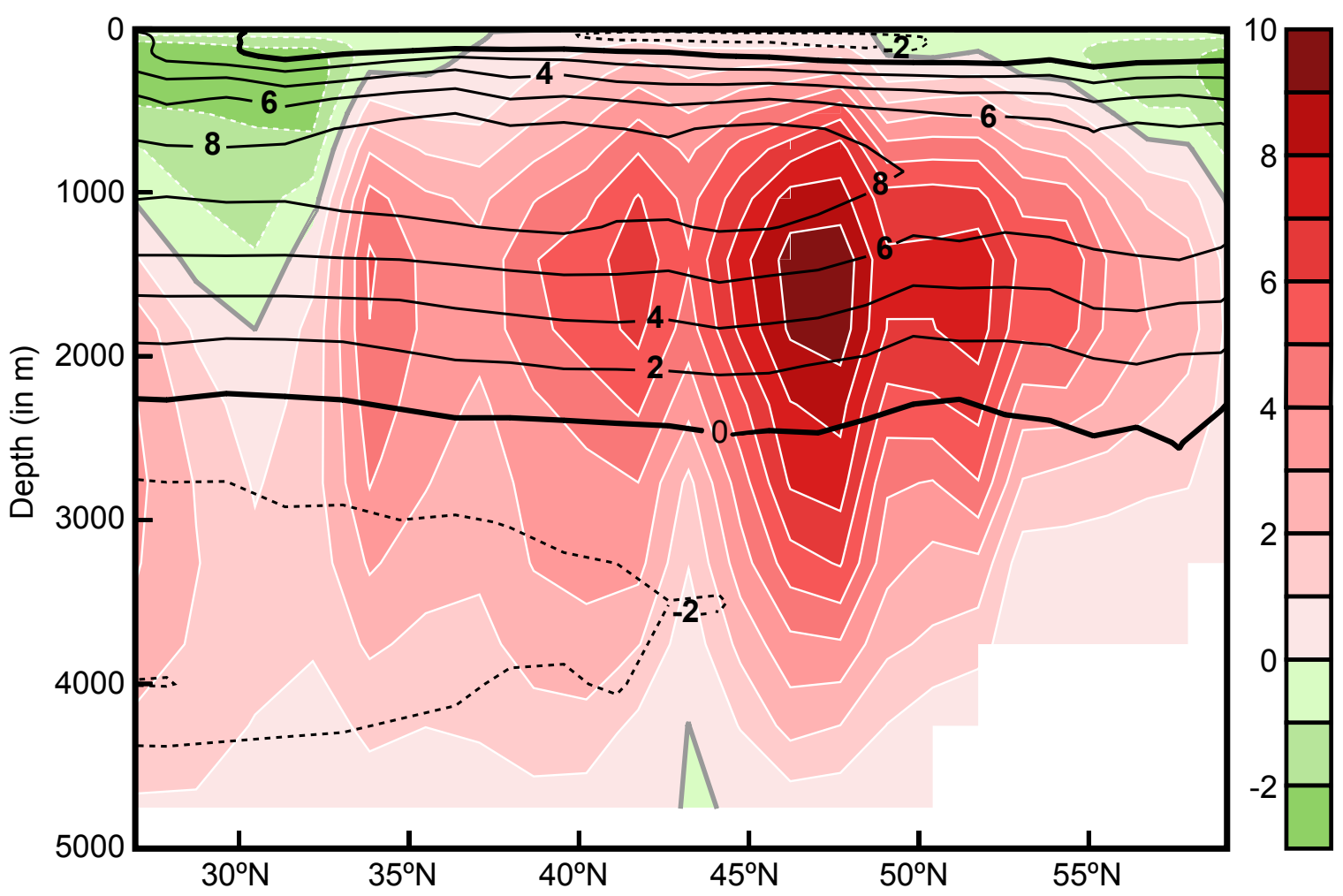

296 Figure 3: Long-term mean of the northward thermal wind transport in the North Atlantic (shaded, in Sv) as computed from the density fields at the coastal boundaries following Equation 1. The mean Atlantic meridional overturning circulation streamfunction (also including the Ekman transport) is superposed in contours (also in Sv).

302 profile at the same latitude. From Equation 2, increased northward thermal wind

303 transport is only possible when $\rho_{\mathrm{w}}>\rho_{\mathrm{e}}$. This implies that the MOI-48N can be interpreted

304 in terms of the thermal wind only below $300 \mathrm{~m}$, as the zonal gradient is reversed above

305 this level. More precisely, the strongest positive west-to-east density gradient is

306 established between 300 and 1000 m, enhanced simultaneously by denser waters at the

307 west and lighter at the east side of the basin. The climatological density gradient is also

308 stronger at these subsurface levels (black contours in Fig. 4). 


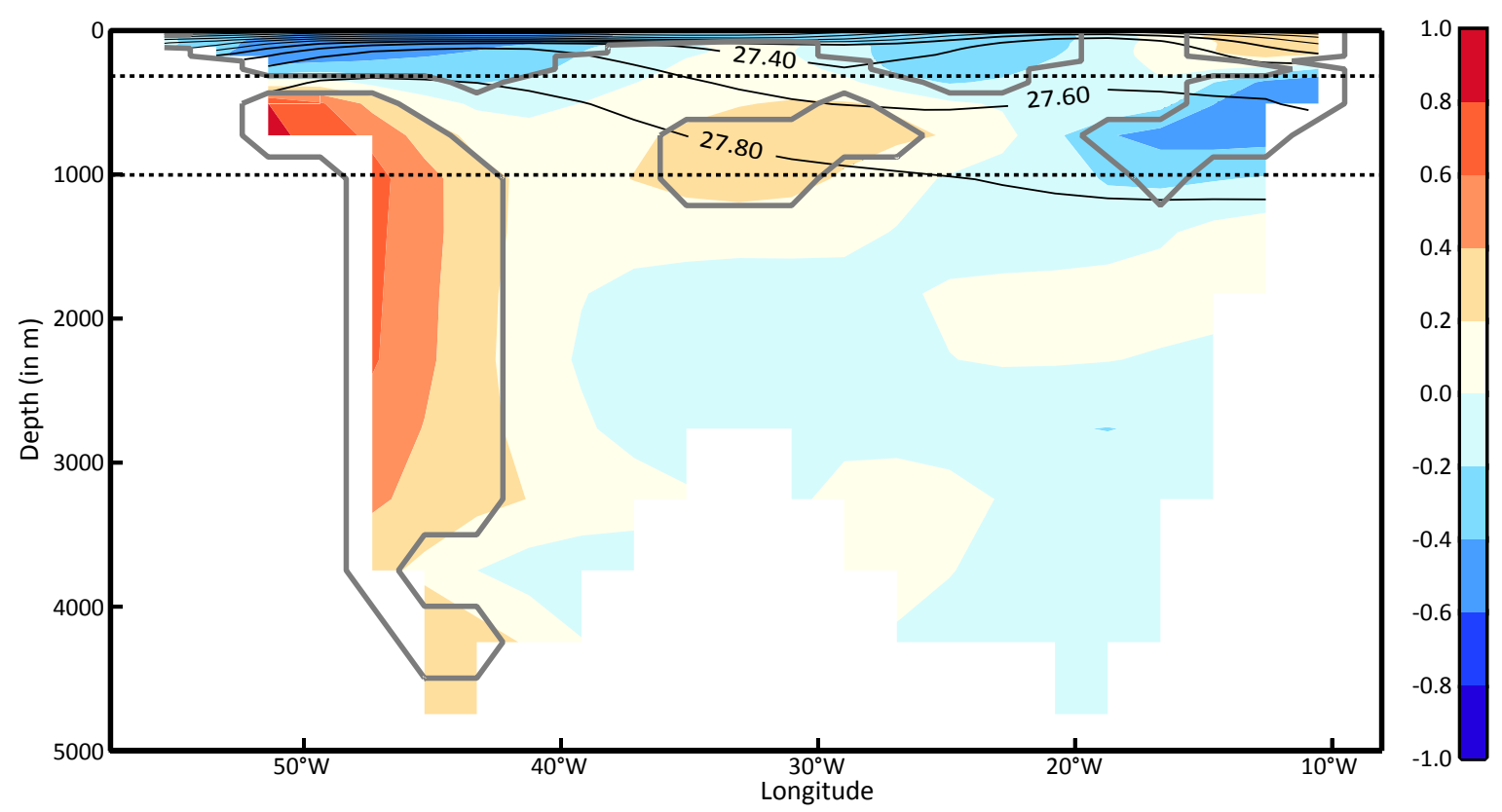

310 Figure 4: Correlation profile (depth-longitude) between the MOI-48N and local density (referenced to the 311 sea surface) at the same latitude. Significant values at the $95 \%$ confidence level are enclosed by the thick 312 grey contours. Black thin contours describe the background density stratification in contour intervals of $0.2 \mathrm{~kg} / \mathrm{m}^{3}$. Horizontal dotted lines delimit the levels at which the $\rho_{\text {west }}-\rho_{\text {east }}$ gradient is strongest.

315 As expected from Figure 4, the spatial correlations between MOI-48N and the vertically

316 averaged subsurface density fields (300-1000m, Figure 5a) are consistent with a basin-

317 wide northward thermal wind response. Strong positive correlations appear all along

318 the western coast of North America, with maximum values near the Labrador Sea and

319 east of Nova Scotia. Negative correlations are observed in the convection region south

320 of Iceland (green lines in Figure 5) and near the coasts of France and Spain. A rather

321 different picture emerges for the upper ocean (Figure 5b), more characterized by a

322 north-south dipole at subpolar latitudes, probably due to other contributions than the

323 thermal wind. The advective mechanism discussed in Escudier et al. (2013) has in

324 particular been shown to exhibit maximum signals at these levels. All of the above

325 suggests that the two modes might be operating at two different depth ranges. 
a) Density mean 300-1000

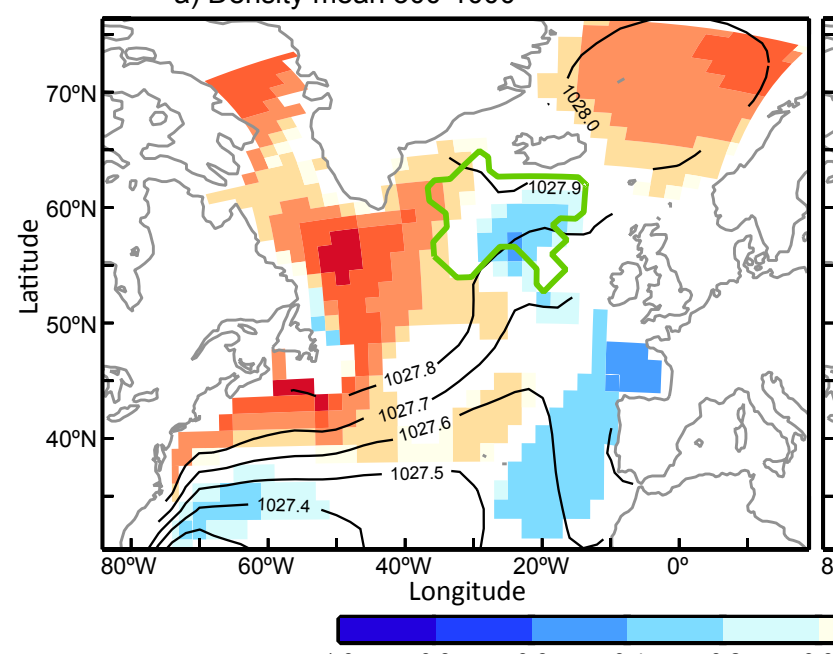

b) Density mean 0-300

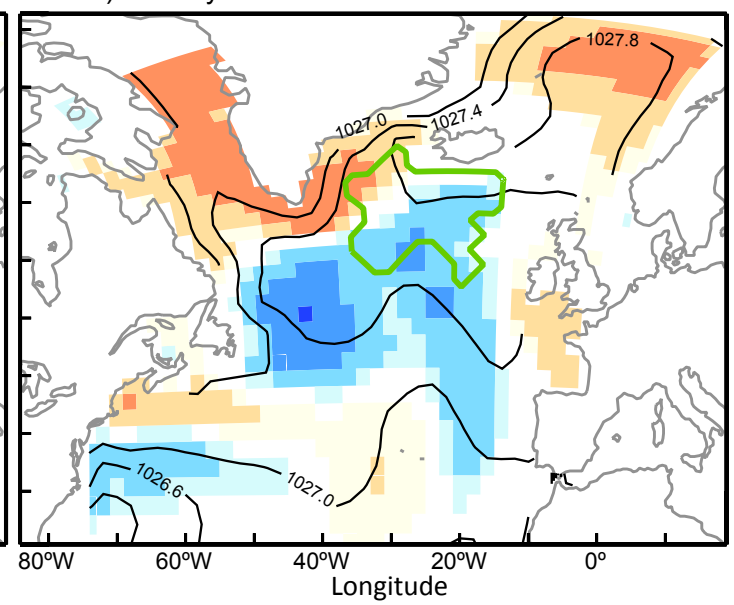

Figure 5: Correlation maps between the MOI-48N index and the vertically averaged density between: a) $300-1000 \mathrm{~m}$ and b) $0-300 \mathrm{~m}$. Only those correlation coefficients significant at the $95 \%$ confidence level are shown. The background density field is represented in black contours. The green thick contour line encloses the region of convection South of Iceland.

332

Now that the optimal depths and regions contributing to the intensification of the northward thermal wind transport are well constrained, we can verify whether the positive density anomalies at the western side of the basin have propagated from the east, as it would be expected if the westward propagation from the subsurface basin mode was present. This is addressed in Figure 6. The first two columns represent the regressions at different lags between the standardized MOI-48N index and the subsurface (i.e. 300-1000m) density averaged over two different latitude ranges. In the

340 subpolar region (i.e. 34 to $65^{\circ} \mathrm{N}$ ) positive density anomalies are indeed formed near

$34130^{\circ} \mathrm{W}$ and propagate slowly to the west reaching the coast about 5 years later, when the

342 AMOC becomes maximum (lag zero). This evolution is coherent with the multidecadal

343 subsurface basin mode. However, no propagation of anomalies of opposite sign

344 reaching the western side of the basin is observed at subsequent lags. This latitudinal

345 band is the same where Sévellec and Fedorov (2013) identified their westward

346 propagation. Yet, they observed it in the upper ocean, where our model presents an

347 eastward propagation (not shown) and where the advective mechanism of Escudier et

348 al. (2013) mainly takes place. When the analysis is restrained to the northernmost part 
349 of the region, where the zonal density gradient is strongest (i.e. $50-65^{\circ} \mathrm{N}$ ), the westward

350 propagation is more clear. The Hovmöller in Figure $6 \mathrm{~b}$ shows how positive and negative

351 density anomalies move westwards with bi-decadal periodicity $(T=20$ years), in

352 accordance with the changes in the AMOC. These features remain coherent for density

353 anomalies integrated down to $3000 \mathrm{~m}$ (not shown). By contrast, no basin-wide

354 westward propagation of density anomalies is observed at the surface levels (Figure 6c).
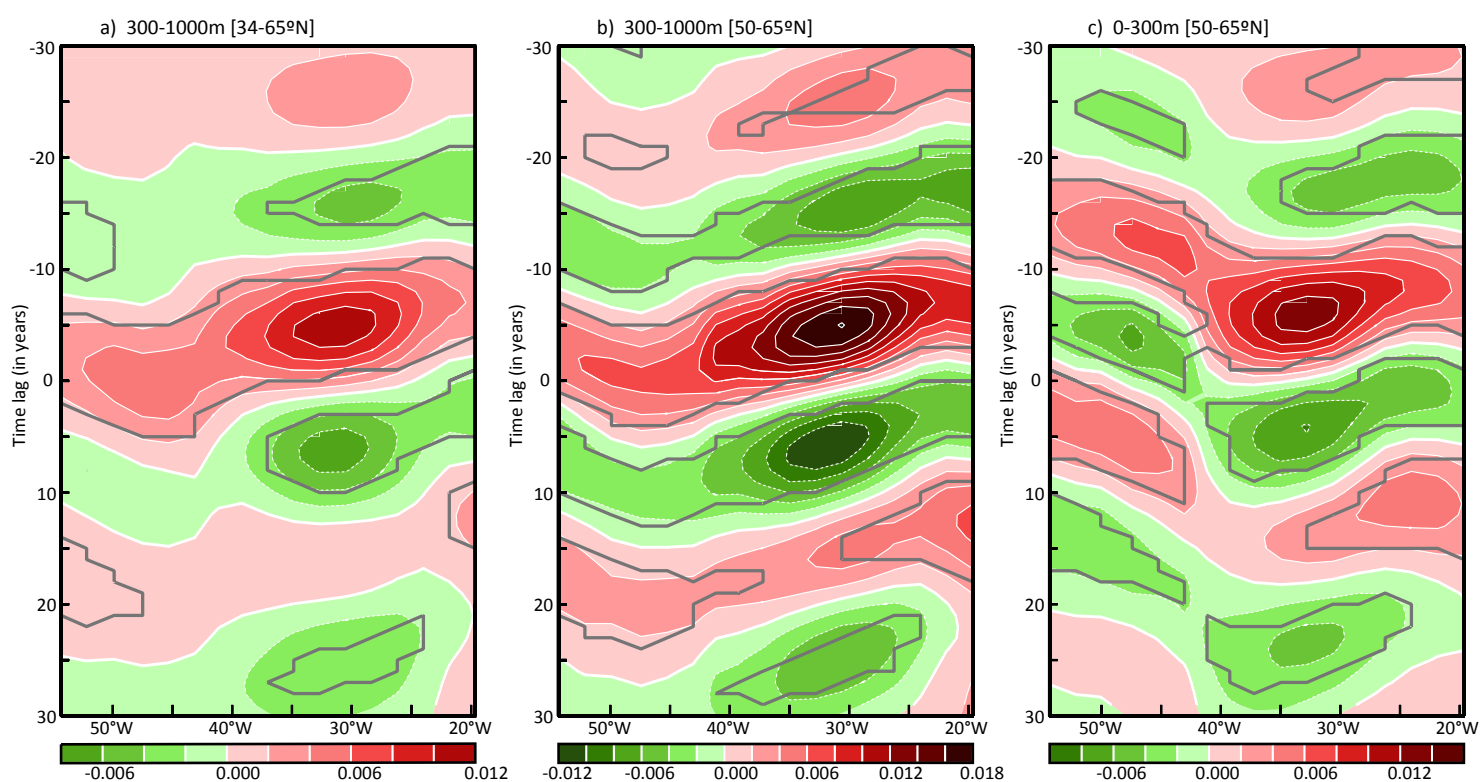

Figure 6: Hovmöller plot (Time lag vs. Longitude) of the regression (in $\mathrm{kg} / \mathrm{m}^{3}$ ) between the standardized MOI- $48 \mathrm{~N}$ and the meridionally averaged density anomalies at: a) $300-1000 \mathrm{~m}$ in the latitude band 34$65^{\circ} \mathrm{N}$; b) $300-1000 \mathrm{~m}$ in $50-65^{\circ} \mathrm{N}$ and c) $0-300 \mathrm{~m}$ in $50-65^{\circ} \mathrm{N}$. Significance is assessed as in Figure 4.

359

360

To determine the role of the mean zonal flow in explaining the propagation, the mean

zonal velocities in the North Atlantic are compared qualitatively to the evolution of

362 density anomalies (Figure 7), represented by the correlation contours of $r= \pm 0.5$ between the MOI-48N and the vertically averaged density fields at different lags. In the

364 upper ocean (Figure 7a), where the advective mechanism is at play, correlation

365 contours describe a loop across the subpolar gyre as the AMOC strengthens (lags -10 to

3660 ) and weakens (lags 0 to 6), with an excursion of anomalies into the Nordic Seas.

367 Westward advection is only observed in the northern subpolar gyre and is almost

368 exclusively confined to the EGC pathway, whereas eastward advection only occurs in 
369 the south, in a region with predominant mean eastward currents. All of this supports

370 the major role of the mean subpolar gyre currents already described in Escudier et al.

371 (2013). A somewhat different picture is found for the subsurface levels (Figure 7b),

372 where mean currents are comparably weaker. Positive density anomalies start at lag -8

373 in the region south of Iceland and move westward across a wide latitudinal range $(\sim 56-$

$37467^{\circ} \mathrm{N}$ ), including areas of positive (i.e. eastward) mean zonal velocities. This is possible

375 due to the contribution of the geostrophic self-advection and $\beta$-effect terms described in

376 Section 2.3, two key features of the subsurface basin mode. Note that, as expected, the

377 propagation is faster in the EGC region, where mean zonal velocities are negative. These

378 fast-propagating anomalies reach the western Greenland Sea at lag -6 , and feed the

379 Labrador Sea Current going south along the coast. The presence of this outflow is hinted

380 by the eastward propagating anomalies from 55 to $50^{\circ} \mathrm{W}$ in Figure $6 \mathrm{~b}$. At lag -2 , the

381 density anomalies from the Labrador Current merge back with the anomalies

382 propagating slowly outside of the EGC region, reaching the Newfoundland coast at this

383 stage. In the immediate subsequent lags, there is a fast adjustment along the western

384 boundary that strengthens the zonal density gradient and thus the AMOC. Note the

385 appearance at lag 2 of negative correlation contours in the region of convection south of

386 Iceland, also propagating slowly to the west outside of the EGC region, consistently with

387 the oscillatory basin mode. 
a) $0-300 \mathrm{~m}$

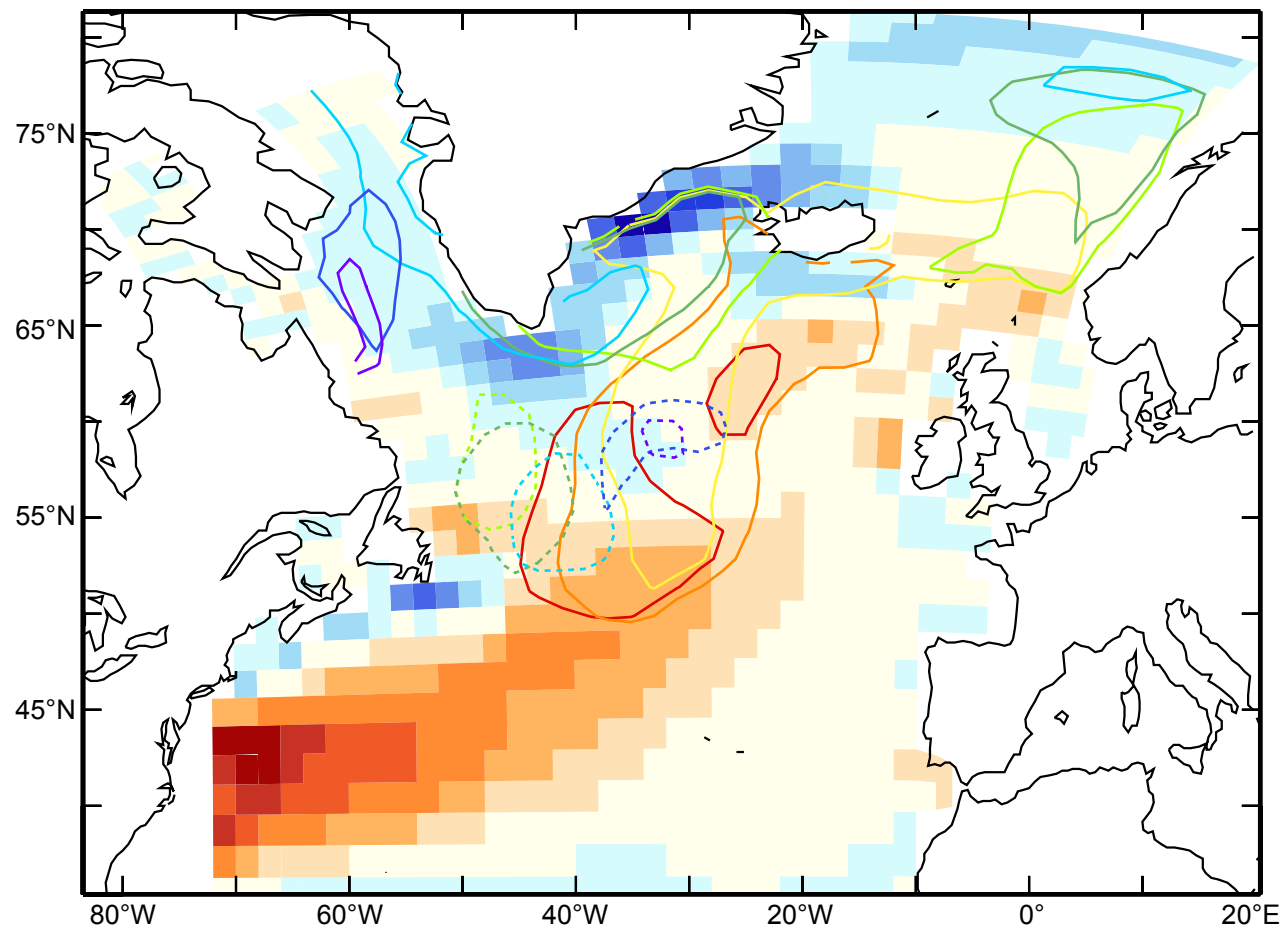

b) $300-1000 \mathrm{~m}$

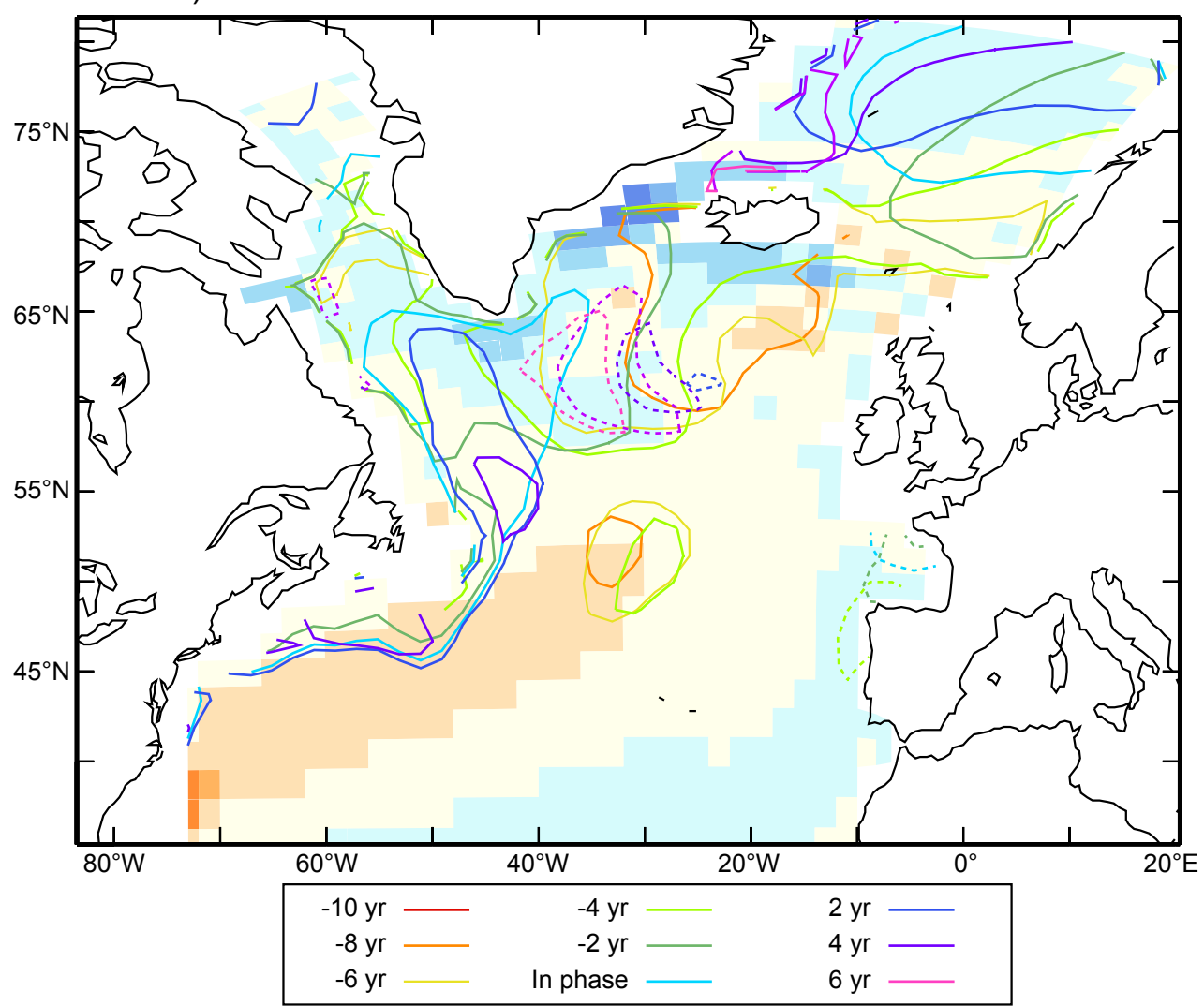

Figure 7: Vertically averaged zonal velocities (shaded, in m/s) in the levels: a) 0-300 m; b) 300-1000 m. 
393 Further evidence of the basin mode propagation is provided in Figure 8a, showing the

394 lead-lag regressions of the normalized MOI-48N with the vertically averaged density 395 and velocity anomalies between 300 and $1000 \mathrm{~m}$. The first panel corresponds to a weak

396 AMOC situation (-T/2; i.e. 10 years before the MOI-48N peaks), and shows a negative 397 zonal density gradient $\left(\rho_{\text {west }}<\rho_{\text {east }}\right)$ leading to a reduced northward transport via

398 thermal wind balance. South of Iceland and north of $50^{\circ} \mathrm{N}$ there is a positive cell of

399 density anomalies, also present in the upper layer (Figure 8b), generating by 400 geostrophy a cyclonic flow response similar to the one described in Sévellec and Fedorov

401 (2013). This cyclonic response, through an interaction with the background density field

402 (Figure 5, black contours), also contributes to the westward displacement. The self-

403 advection term is higher in the regions where the south-to-north background density 404 gradient is stronger, and can thereby compensate the eastward mean zonal velocities at 405 the eastern side of the basin (Figure 7b). Thus, both contributions along with the $\beta$ 406 effect - of smaller amplitude than them but by definition always negative - can account 407 together for an effective basin-wide westward propagation of the initial density 408 anomalies. Indeed, at lag $-T / 4$ the cyclonic cell is visibly displaced to the west, growing 409 also in strength, notably along the Greenland coast. Note that at this stage the cyclonic 410 cell extends also into the upper ocean (Figure 8b), where it intensifies the southward 411 transport through the Denmark Strait, and therefore also the EGC strength. This link 412 will be discussed in more detail in section 4.2. Strengthened AMOC situations (lag zero) 413 set up when the positive anomalies have reached the Labrador coast and new negative 414 anomalies (inducing this time an anticyclonic geostrophic response) are formed south 415 of Iceland, thus reversing the initial zonal gradient and intensifying the northward 416 transport through thermal wind balance. These negative density anomalies appear as a 417 result of a reduction in convection following the arrival of negative upper density 
418 anomalies from the Denmark Strait and Labrador regions (Figure 8, lags $-T / 4$ and $-T / 2$ ).

419 For the positive lags (AMOC leading) $T / 4$ and $T / 2$ the opposite phase of the propagation

420 takes place, this time with the negative density anomalies moving eastward in response

421 to the associated anticyclonic flow bringing lighter waters into the west (coming from

422 southern regions) and denser waters into the eastern flank (advected from the north). 
a) $300-1000 \mathrm{~m}$
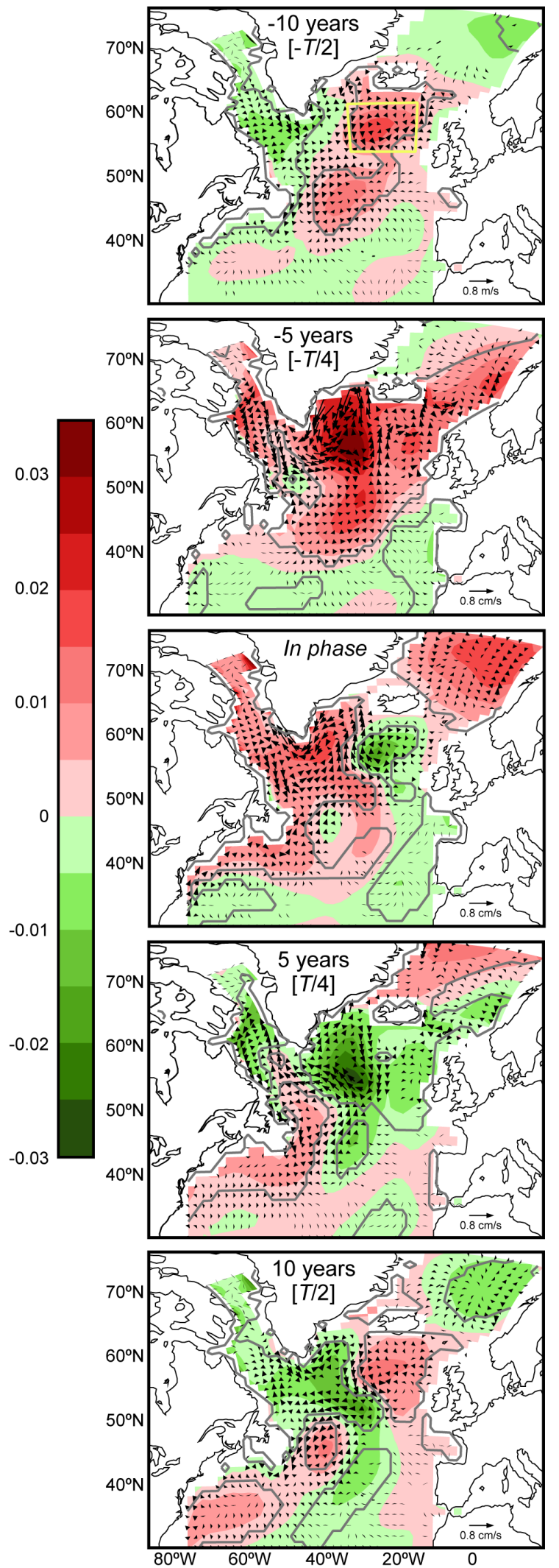

b) $0-300 \mathrm{~m}$
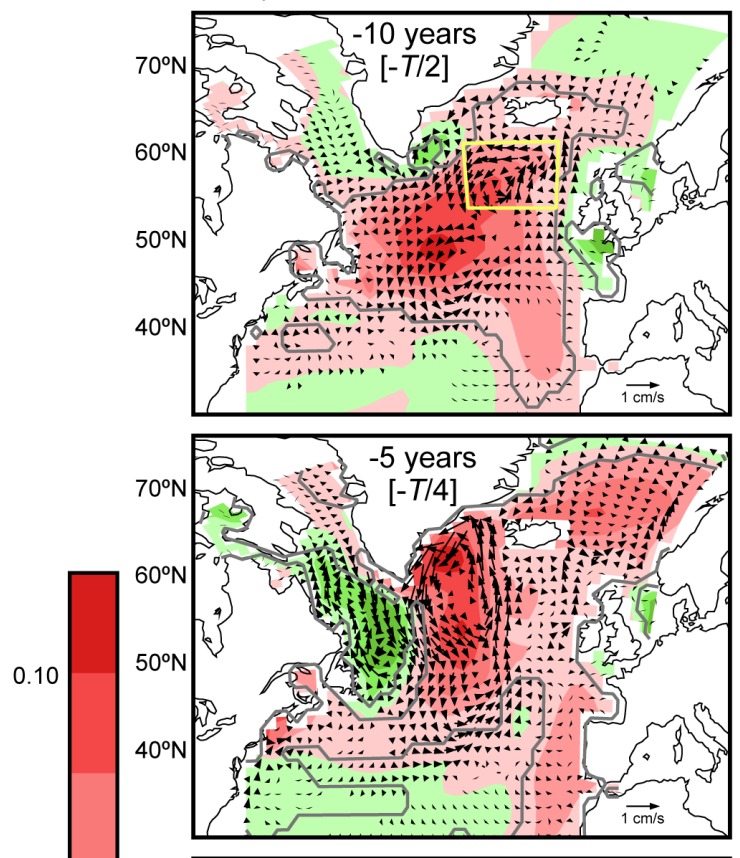

0.05

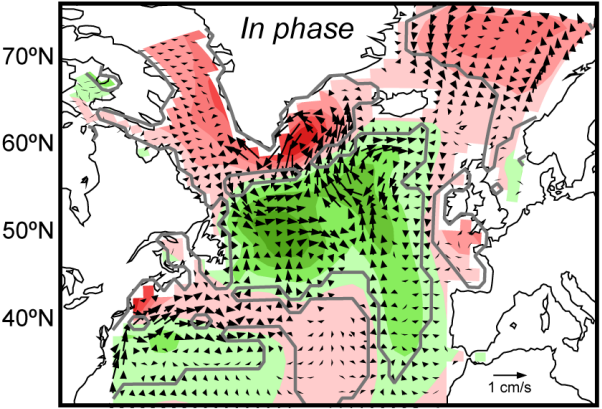

$-0.05$
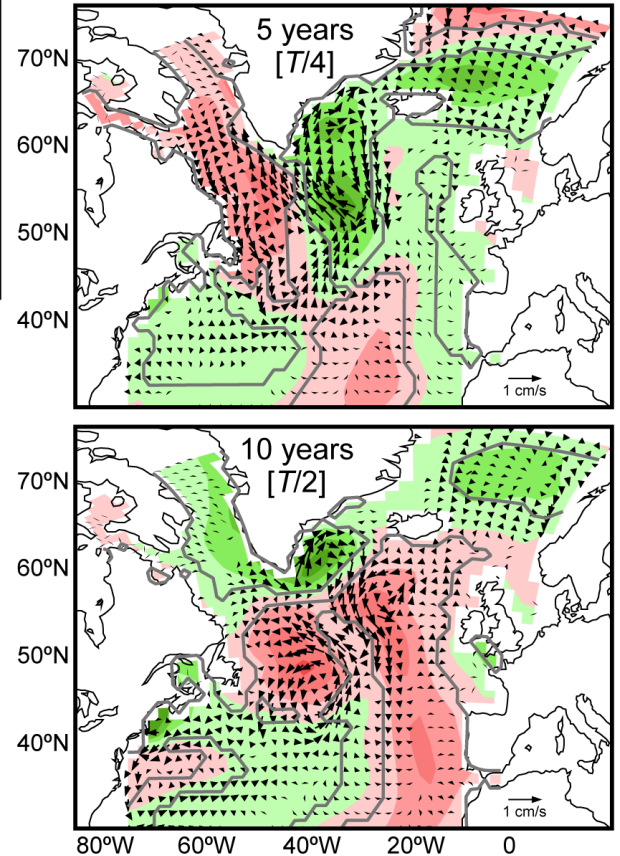

424 Figure 8: Time-lag regressions between the normalised MOI-48N index and both the vertically averaged density (shaded) and ocean velocity (vectors) anomalies in: a) 300-1000 m layer; b) 0-300 m layer. The 426 lag is written in fractions of the period $T$ (20 years). Significance is assessed as in Figure 4 . The yellow box 427 encloses the region where the index $\rho_{\mathrm{NE}-\mathrm{Atl}}$ is defined. 
428 The balance of evidence presented here is thus consistent with the existence of a

429 multidecadal basin mode in subsurface $(300-1000 \mathrm{~m})$ linked to the variability of the

430 AMOC. Furthermore, this mechanism operates at a similar timescale and in the same

431 basin as the upper-ocean (0-300m) advection mechanism from Escudier et al (2013).

432 We now assess whether both mechanisms are independent, or interact with each other.

\section{4. Interactions between the two bi-decadal modes}

434 Given that both mechanisms vary at similar timescales and share several dynamical

435 components, our working hypothesis is that both are coupled. There are two key 436 quantities that could explain a link between the two modes: deep convection and the $437 \quad E G C$.

438 4.1 From the upper ocean advective mechanism to the subsurface basin mode: the role

439 of convection

440 The most evident link is ocean convection, because it connects the upper and the deeper

441 ocean. Indeed, winter convection enhances oceanic heat release to the atmosphere,

442 resulting in a net cooling and densification of the water column (Swingedouw et al.,

443 2007). In the coupled model, the convection region located south of Iceland (Figure 5)

444 is the one showing strongest correlations with the AMOC (Escudier et al., 2013). Its

445 variability is driven by anomalies in upper ocean salinity, which are built up in the

446 Labrador Sea and advected eastward by the subpolar gyre. The arrival of positive

447 salinity anomalies coincides with minimum values in the AMOC strength, a situation

448 that weakens the meridional heat transport and gradually cools and densifies the upper

449 layers in the North Atlantic. This effect of the AMOC on the vertical density structure in

450 the convection region is illustrated in Figure 9. The MOI-48N is anticorrelated with

451 density anomalies near the surface (mostly thermally driven), but also directly

452 correlated with salinity-driven density anomalies at depth (Figure 9). Thus, weakened 
453 AMOC situations reduce the vertical stratification, and contribute to facilitate deep

454 convection when the positive surface salinity anomalies arrive. Following the increases

455 in convection south of Iceland, anomalously dense waters are formed from the surface

456 down to $2000 \mathrm{~m}$ depth (Figure 10), thus including the depth range where the basin

457 mode propagation is observed. These are most probably the same density anomalies

458 observed at lag $-T / 2$ in the northeast Atlantic (NE-Atl, yellow box in Figure 8), both in

459 the upper (0-300) and intermediate (300-1000m) levels, and propagating westward in

460 response to the induced anomalous cyclonic flow. This is supported by Figure 11a,

461 showing that upper $1000 \mathrm{~m}$ density anomalies in the northeast Atlantic box ( $\rho_{\mathrm{NE}-\mathrm{Atl}}$ ) are

462 highly correlated with mixed layer depth changes in the region south of Iceland (MLDs-

463 Ice; green contours in Figure 5). These anomalies lead the changes in the AMOC by about

4648 years, which is the time they require to reach the western coast, enhance the zonal

465 density gradient and thus increase the meridional thermal wind transport, as

466 demonstrated by Sévellec and Fedorov (2015). It is therefore through a stimulation of

467 subsurface basin mode that the advective mechanism at the surface, and ultimately

468 convection, comes to impact the variability of the AMOC several years after. Following

469 Sévellec and Fedorov (2015) we have been able to provide a mechanistic explanation to

470 the long delay between convection south of Iceland and the AMOC response previously

471 reported in Escudier et al. (2013). 


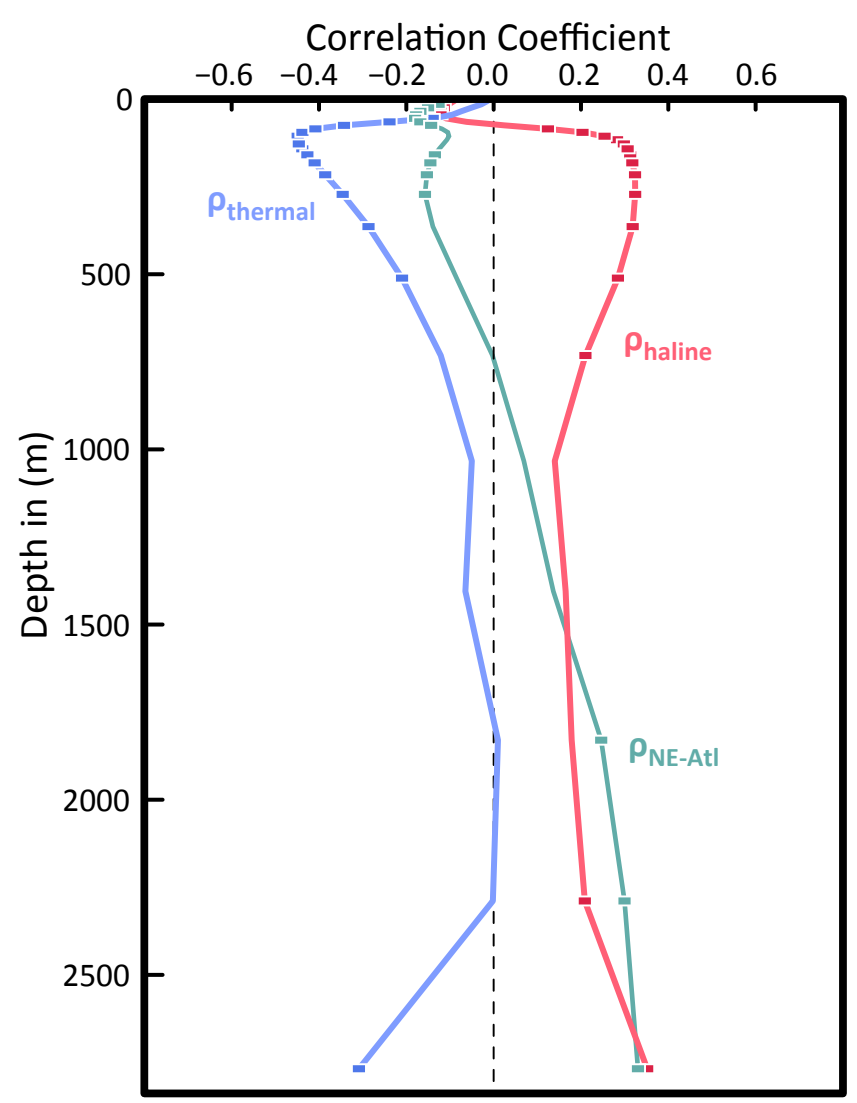

Figure 9: Vertical profile of the correlations between the MOI-48N index and density anomalies in the region of convection in the eastern North Atlantic (enclosed by the green contour in Figure 5). Both the full density and the related thermal and haline contributions are shown for comparison. Significant values at the $95 \%$ confidence level are highlighted with dots.

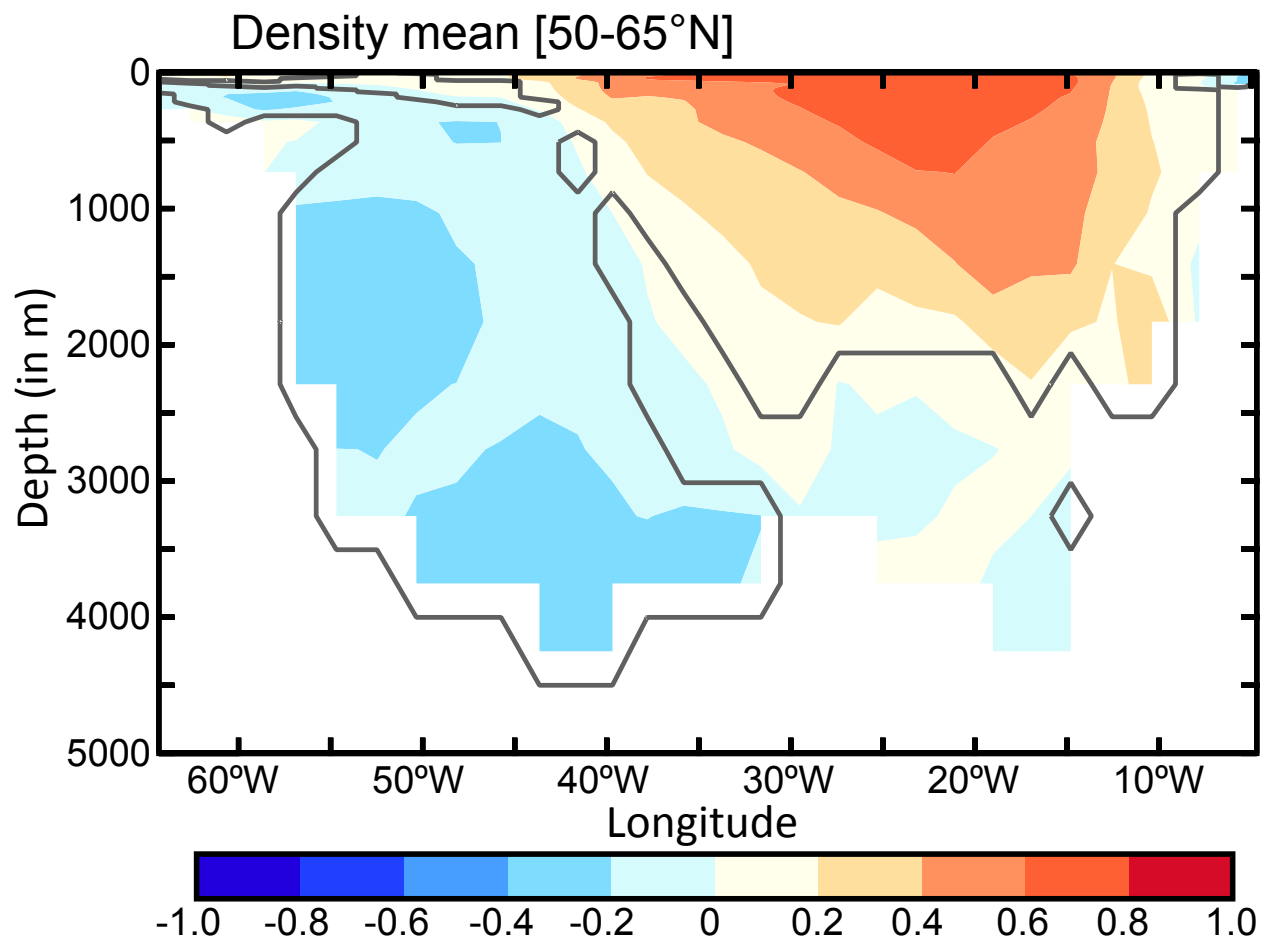

Figure 10: Correlation profile (longitude-depth) between an index of North Atlantic convection (region enclosed by the green contour in Figure 5) and the latitudinally averaged densities between $50-65^{\circ} \mathrm{N}$. The index of convection is defined as the annual mixed layer depth mean in the region. Significance is assessed as in Figure 4. 


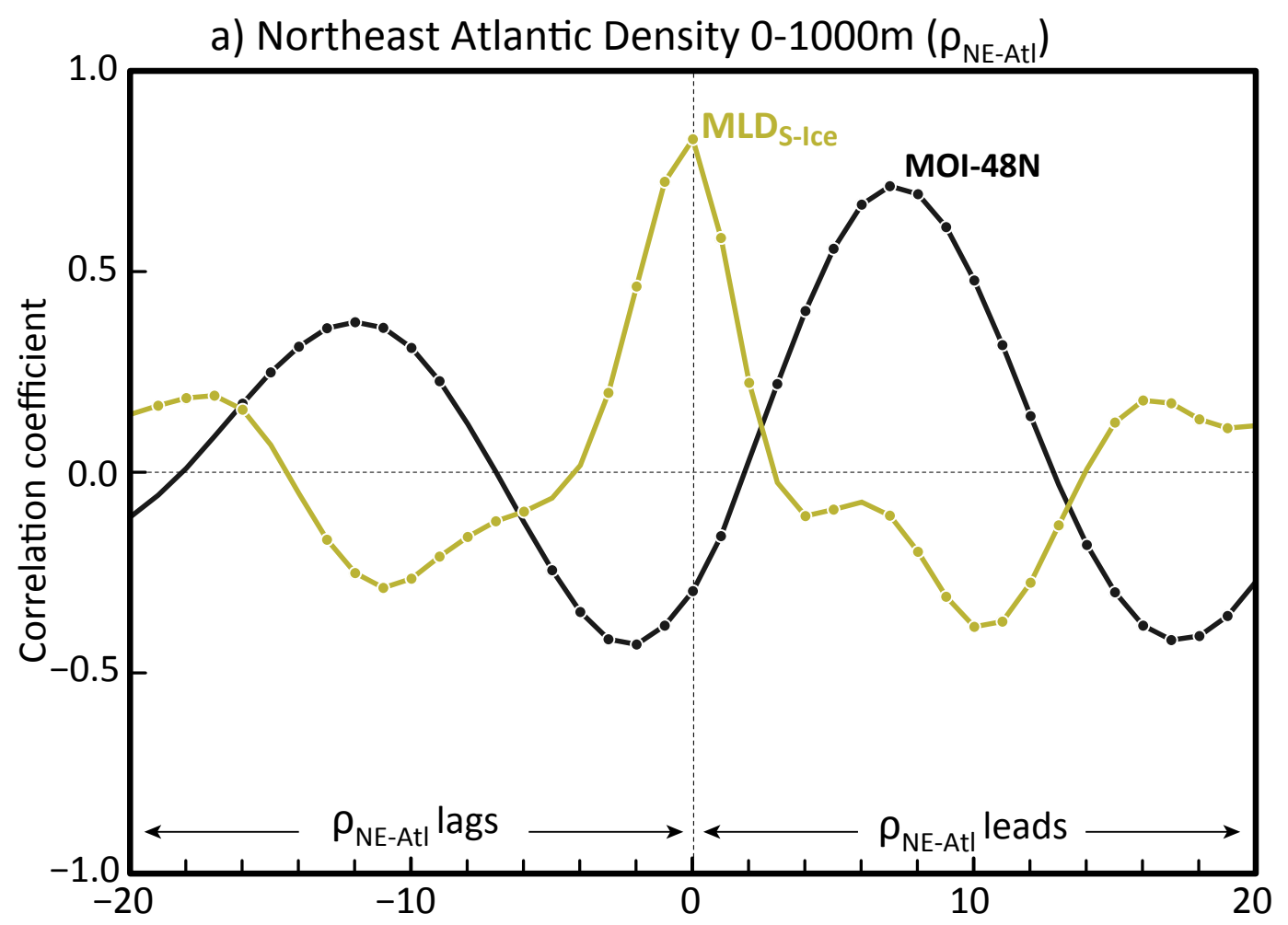

b) East Greenland Current (EGC)

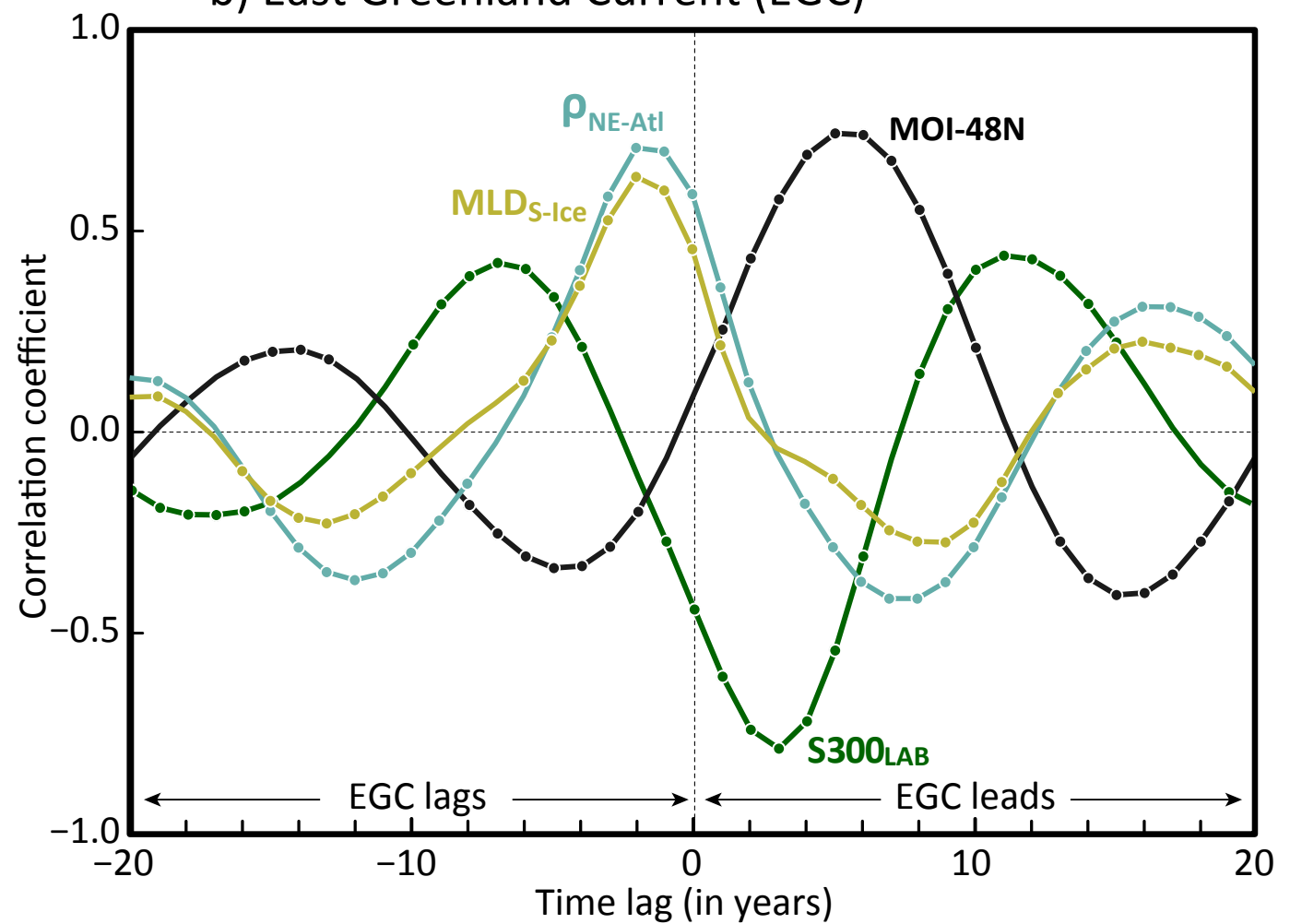

Figure 11: Lead-lag time correlation plot of several indices with: a) Northeast Atlantic density in the upper $1000 \mathrm{~m}$ and b) the East Greenland Current intensity. Significant values at the $95 \%$ confidence level are highlighted with dots. 
4874.2 From the subsurface basin mode to the advective mechanism in the upper ocean:

488 the role of the EGC

489 In order to understand whether and how the subsurface basin mode feeds back onto the

490 subpolar-gyre advective mode at the surface, we focus on the EGC (cf. Escudier et al.,

491 2013). Indeed, this upper-ocean current, linking the Arctic waters with the subpolar

492 gyre, is essential to explain the phase reversal of the salinity anomalies advected by the

493 subpolar gyre in the advective mechanism. Here, we use the same definition as in

494 Escudier et al. (2013): the EGC is calculated as the outflow of waters through the

495 Denmark Strait with mean salinity values lower than 34 psu. These are localized in the

496 upper $200 \mathrm{~m}$ near the Greenland coast. In Escudier et al. (2013), EGC strengthenings

497 were explained by a decrease in sea-ice cover in the Nordic Seas, producing an 498 anomalous atmospheric cyclonic response that subsequently intensified Ekman

499 transport through the Denmark Strait. This link, even if physically consistent, was found

500 in that study to be somewhat weak. We revisit this interpretation under our new

501 framework, in which the subsurface basin mode propagation is also at play. Figure 8

502 already showed that at the lag -T/4 (i.e. 5 years before an AMOC peak), the anomalous

503 cyclonic cell, present both in the surface and the subsurface, is located near the

504 Greenland coast, with a particularly intense southward transport branch at its western

505 flank. This explains why EGC variability is strongly linked with the appearance, 5 years

506 before (although with maximum correlation for a 2-year lead time), of the positive

507 density anomalies in the northeast Atlantic (Figure 11b), which was shown before to be

508 associated with increased convection. This EGC change, fueled by the anomalous

509 cyclonic cell, is also characteristic of the oceanic adjustment to the large-scale baroclinic

510 Rossby waves described in Sévellec and Fedorov (2013). EGC changes translate into an

511 increased export of fresher waters into the subpolar gyre, which reverses the sign of the 
512 initial salinity anomalies in the upper Labrador Sea ( $3300_{\mathrm{LAB}}$ ). This process is key to

513 sustain the 20-year cycle in the advective mechanism. Here, we have shown that it is

514 convection, the associated changes in subsurface density, and their later impact on the

515 EGC that provide the two-way coupling between the two mechanisms.

516

517

518

519

\section{Summary and Discussion}

521 To summarize, an updated view of the processes and interactions responsible for the bi-

522 decadal AMOC variability in IPSL-CM5A is provided in the schematic of Figure 12. Until

523 now, AMOC variability in the model was explained through salinity-driven changes in

524 the deep convection regions. By characterizing and including the subsurface basin mode

525 we are now able to explain the process by which convection impacts the AMOC.

526 Furthermore, the two modes can coexist and show the same preferential variability

527 because they have accommodated to interact constructively with each other. 
528 In essence, the whole cycle develops as follows. Upper ocean positive salinity anomalies

529 are advected by the subpolar gyre from the Labrador Sea into the sinking regions south

530 of Iceland (in 5 years), where they enhance deep convection and a negative thermal

531 anomaly is formed from the surface down to $2000 \mathrm{~m}$. This induces a geostrophic

532 response, characterized by a cyclonic flow that propagates westwards in the subsurface

533 as a result of its interaction with the mean meridional density gradient. As the

534 anomalies reach the eastern Greenland coast 2 years after, the associated cyclonic flow

535 leads at the surface to an intensification of the EGC. This effect on the EGC comes on top

536 of the weak feedback mechanism with sea ice and SLP anomalies in the Nordic Seas

537 already described in Escudier et al. (2013), and contributes to synchronize the two

538 multidecadal modes. At depth, density anomalies continue their westward propagation

539 until they reach the Canadian coast 6 years after, propagating southward along the

540 western boundary current, and establishing a strong zonal gradient that triggers a

541 northward thermal wind response, thus strengthening the AMOC. Phase reversal in the

542 upper ocean is related to the EGC, and its export of fresh waters from the Arctic into the

543 subpolar gyre, building up large anomalies in the Labrador Sea 3 years after (10 years if

544 we count from the beginning of the cycle). Accordingly, the phase reversal in the deeper

545 ocean appears when these negative salinity anomalies reach the vicinity of Iceland 5

546 years later, and debilitate deep convection. Note that at this stage, surface waters over

547 the region are gradually warming, in response to the increase in northward heat

548 transport that follows the strengthened AMOC phase. This suggests that the AMOC plays

549 a preconditioning role in the phase reversal of convection.

550 Observational records do support a prominent 20-year time scale in the North Atlantic,

551 supported, for instance, by sea level estimates at the east and western boundaries

552 (Frankcombe \& Dijkstra, 2009), and also in reconstructed estimates of Greenland 
553 temperature (Chylek et al., 2011) and the sea ice edge in the Nordic Seas (Divine \& Dick,

554 2006). Regarding the specific variables involved in our mechanism, there exist evidence

555 of decadal fluctuations in salinity measurements of the Labrador Sea, shaped by the

556 occurrence of the Great Salinity Anomalies (Belkin et al., 1998; Swingedouw et al., 2015).

557 It is not clear, however, if they also present a modulation at 20 years. Only short records

558 for the EGC variability are available, insufficient to assess its multidecadal changes.

559 There is, however, a long proxy record for local SST in its vicinity that exhibits a

560 significant peak at 20 years (Sicre et al., 2008). All of the above suggests that some of

561 the features of our mechanism might be realistic. Yet, it is important to keep in mind

562 that some other aspects are inherent to the model and its main biases. For example, one

563 important limitation of IPSL-CM5A and former versions is its inability to represent deep

564 convection in the Labrador Sea, due to too fresh local climatological conditions over the

565 area (Swingedouw et al., 2007). This misrepresentation is probably decisive to allow for

566 the salinity advection mechanism in Escudier et al. (2013) and its particular

567 arrangement with the subsurface basin mode. Otherwise, EGC-driven salinity anomalies

568 would first arrive and impact the Labrador region, being partly transformed into a

569 thermal anomaly reaching deeper levels. Hence, it could modify the upper and lower

570 ocean signals being advected by the subpolar gyre and possibly compromise the

571 westward propagation from the region south of Iceland.

572 Our results nevertheless support the coexistence of a multidecadal subsurface basin

573 mode with an advective mechanism at the surface, and prompts for further

574 investigations in other coupled climate models. In IPSL-CM5A, the westward

575 propagation is excited and sustained by salinity-driven deep convection following

576 surface oscillatory mechanism (Escudier et al., 2013), and not simply by stochastic

577 forcing from the atmosphere like other analyses suggest (Frankcombe et al., 2009; 
578 Sévellec et al., 2009). This may explain why the 20-year variability is so pronounced in

579 IPSL-CM5A. Identifying this kind of mechanism in other coupled climate models, with

580 different representations of North Atlantic convection and the AMOC, is essential to

581 ascertain whether the basin mode propagation is actually predominant or if, on the

582 contrary, its signal becomes strongly damped by the influence of the atmosphere.

583 Tulloch and Marshall (2012) described a similar mechanism in both CCSM3 and the

584 GFDL Climate Model version 2.1 (CM2.1), involving a westward propagation of

585 subsurface density anomalies in a timescale broadly consistent with the transit of first

586 baroclinic mode Rossby waves, which affects the AMOC through a thermal wind

587 response. Interestingly, in both models a predominant 20-year time-scale for the AMOC

588 was also identified, despite some differences in their upper ocean variability. This

589 suggests that the subsurface basin mode may be the key mechanism to generate bi-

590 decadal AMOC variability, and that it can appear under other coupled model

591 configurations. In the particular case of our study, we have seen that the subsurface

592 basin mode is also compatible with an upper ocean mechanism driven by EGC

593 variations, which share similarities with some of the observed Great Salinity Anomalies

594 (Swingedouw et al., 2013, 2015).

595 Acknowledgements :

596 This study was partly funded by the EU project SPECS funded by the European

597 Commission's Seventh Framework Research Programme under the grant agreement 598 308378, by the MORDICUS Project funded by the Agence Nationale de la Recherche 599 under grant agreement ANR-13-SENV-0002-02, and by the Natural and Environmental 600 Research Council UK (MESO-CLIP, NE/K005928/1). The authors thank Alexey V. 601 Fedorov for fruitful discussions on the topic. 
604 Aumont, O., Bopp, L., 2006. Globalizing results from ocean in situ iron fertilization studies.

605 Global Biogeochemical Cycles, 20, GB2017.

606 Belkin, I.M., Levitus, S., Antonov, J., Malmberg, S.-A., 1998. "Great Salinity Anomalies" in

607

608 the North Atlantic. Progress in Oceanography, 41, 1-68.

609

6102009.

Bretherton, C. S., Widmann, M., Dymnikov, V. P., Wallace, J. M., Bladé, I., 1999. The

611 Cheng, W., Bleck, R., Rooth, C., 2004. Multi-decadal thermohaline variability in an ocean-

612 atmosphere general circulation model. Climate Dynamics, 22, 573-590.

613 Chylek, P., Folland, C.K., Dijkstra, H.A., Lesins, G., Dubey, M.K., 2011. Ice core data

614 evidence for a prominent near 20 year time scale of the Atlantic Multidecadal Oscillation.

615 Geophysical Research Letters, 38, L13704.

616 Colin de Verdière, A., Huck, T., 1999. Baroclinic instability: An oceanic wavemaker for

617

618

619

620 interdecadal variability. Journal of Physical Oceanography, 29, 893-910.

Cronin, T.M., Farmer, J., Marzen, R.E., Thomas, E., Varekamp, J.C., 2014. Late Holocene sea level variability and Atlantic Meridional Overturning Circulation. Paleoceanography, 2014PA002632.

621 Cunningham, S.A., Kanzow, T., Rayner, D., Baringer, M.O., Johns, W.E., Marotzke, J., 622 Longworth, H.R., Grant, E.M., Hirschi, J.J.-M., Beal, L.M., Meinen, C.S., Bryden, H.L., 623 2007. Temporal Variability of the Atlantic Meridional Overturning Circulation at 26.5 N. 624 Science, 317, 935-938.

625 Danabasoglu, G., 2008. On Multidecadal Variability of the Atlantic Meridional Overturning 626 Circulation in the Community Climate System Model Version 3. J Climate, 21, 5524-5544.

627 Delworth, T.L., Manabe, S., Stouffer, R.J., 1993. Interdecadal Variations of the 628 Thermohaline Circulation in a Coupled Ocean-Atmosphere Model. J Climate, 6, 1993-2011.

629 Deshayes, J., Frankignoul, C., 2005. Spectral Characteristics of the Response of the

630 Meridional Overturning Circulation to Deep-Water Formation. Journal of Physical 631 Oceanography, 35, 1813-1825.

632 Divine, D. V., Dick, C., 2006. Historical variability of sea ice edge position in the Nordic 633 Seas. J. Geophys. Res. Ocean, 111, 1-14.

634 Dong, B., Sutton, R.T., 2005. Mechanism of Interdecadal Thermohaline Circulation

635

636

637

638

639 Variability in a Coupled Ocean-Atmosphere GCM. J Climate, 18, 1117-1135.

640 Dufresne, J.L., Foujols, M.A., Denvil, S., Caubel, A., Marti, O., Aumont, O., Balkanski, Y., Bekki, S., Bellenger, H., Benshila, R., Bony, S., Bopp, L., Braconnot, P., Brockmann, P., Cadule, P., Cheruy, F., Codron, F., Cozic, A., Cugnet, D., de Noblet, N., Duvel, J.P., Ethe, C., Fairhead, L., Fichefet, T., Flavoni, S., Friedlingstein, P., Grandpeix, J.Y., Guez, L., Guilyardi, E., Hauglustaine, D., Hourdin, F., Idelkadi, A., Ghattas, J., Joussaume, S., Kageyama, M., 641 Krinner, G., Labetoulle, S., Lahellec, A., Lefebvre, M.P., Lefevre, F., Levy, C., Li, Z.X., 642 Lloyd, J., Lott, F., Madec, G., Mancip, M., Marchand, M., Masson, S., Meurdesoif, Y., 643 Mignot, J., Musat, I., Parouty, S., Polcher, J., Rio, C., Schulz, M., Swingedouw, D., Szopa, S., 644 Talandier, C., Terray, P., Viovy, N., Vuichard, N., 2013. Climate change projections using 645 the IPSL-CM5 Earth System Model: from CMIP3 to CMIP5. Climate Dynamics, 40, 21236462165.

647 Escudier, R., Mignot, J., Swingedouw, D., 2013. A 20-year coupled ocean-sea ice648 atmosphere variability mode in the North Atlantic in an AOGCM. Climate Dynamics, 40, $649619-636$.

650 Feng, Q.Y., Dijkstra, H., 2014. Are North Atlantic multidecadal SST anomalies westward 651 propagating? Geophysical Research Letters, 41, 541-546. 
652 Fichefet, T., Maqueda, M.A.M., 1997. Sensitivity of a global sea ice model to the treatment 653 of ice thermodynamics and dynamics. Journal of Geophysical Research: Oceans, 102, 654 12609-12646.

655 Frankcombe, L.M., Dijkstra, H.A., von der Heydt, A., 2008. Sub-surface signatures of the

656

657 Atlantic Multidecadal Oscillation. Geophysical Research Letters, 35, L19602.

658 Frankcombe, L.M., Dijkstra, H.A., von der Heydt, A., 2009. Noise-Induced Multidecadal Variability in the North Atlantic: Excitation of Normal Modes. Journal of Physical ceanography, 39, 220-233.

660 Frankcombe, L.M., von der Heydt, A., Dijkstra, H.A., 2010. North Atlantic Multidecadal 661 Climate Variability: An investigation of dominant time scales and processes. J Climate, 23, $662 \quad 3626-3638$.

663 Gray, S.T., Graumlich, L.J., Betancourt, J.L., Pederson, G.T., 2004. A tree-ring based 664 reconstruction of the Atlantic Multidecadal Oscillation since 1567 A.D. Geophys. Res. Lett. $66531,2-5$.

666 Hawkins, E., Sutton, R.T., 2007. Variability of the Atlantic thermohaline circulation 667

668

669

670 described by three-dimensional empirical orthogonal functions. Climate Dynamics, 29, 745762.

672 Hirschi, J., Marotzke, J., 2007. Reconstructing the meridional overturning circulation from 673 boundary densities and the zonal wind stress. Journal of Physical Oceanography, 37, 743763.

675 Hourdin, F., Foujols, M.-A., Codron, F., Guemas, V., Dufresne, J.-L., Bony, S., Denvil, S., Guez, L., Lott, F., Ghattas, J., Braconnot, P., Marti, O., Meurdesoif, Y., Bopp, L., 2013. Impact of the LMDZ atmospheric grid configuration on the climate and sensitivity of the IPSL-CM5A coupled model. Climate Dynamics, 40, 2167-2192.

679 Huck, T., De Verdiere, A.C., Weaver, A.J., 1999. Interdecadal variability of the thermohaline circulation in box-ocean models forced by fixed surface fluxes. Journal of Physical 681 Oceanography, 29, 865-892.

682 Jungclaus, J.H., Haak, H., Latif, M., Mikolajewicz, U., 2005. Arctic-North Atlantic 683 Interactions and Multidecadal Variability of the Meridional Overturning Circulation. $J$ 684 Climate 18, 4013-4031.

685 Killworth, P.D., Blundell, J.R., 2007. Planetary Wave Response to Surface Forcing and 686 Instability in the Presence of Mean Flow and Topography. Journal of Physical 687 Oceanography, 37, 1297-1320.

688 Killworth, P.D., Chelton, D.B., DeSzoeke, R.A., 1997. The speed of observed and theoretical long extratropical planetary waves. Journal of Physical Oceanography, 27, 1946-1966.

690 Kwon, Y.-O., Frankignoul, C., 2014. Mechanisms of Multidecadal Atlantic Meridional 691 Overturning Circulation Variability Diagnosed in Depth versus Density Space. Journal of 692 Climate, 27, 9359-9376.

693 Madec, G., 2008. NEMO ocean engine. Notes du Pole de Modelisation. Institut Pierre-Simon 694 Laplace (IPSL), No 27.

695 Marshall, J., Scchott, F., 1999. Open-ocean convection: Observations, theory, and models. Rev. Geophys. 37,1-64.

698 J.H., 2012. A multimodel comparison of centennial Atlantic meridional overturning circulation variability. Climate Dynamics, 38, 2377-2388.

700 Mignot, J., Swingedouw, D., Deshayes, J., Marti, O., Talandier, C., Séférian, R., Lengaigne, 701 M., Madec, G., 2013. On the evolution of the oceanic component of the IPSL climate models 702 from CMIP3 to CMIP5: A mean state comparison. Ocean Modelling, 72, 167-184. 

the Atlantic meridional overturning circulation in the last millennium and two IPCC scenarios. Climate Dynamics, 38, 1925-1947.

706 Persechino, A., Mignot, J., Swingedouw, D., Labetoulle, S., Guilyardi, E., 2013. Decadal predictability of the Atlantic meridional overturning circulation and climate in the IPSLCM5A-LR model. Climate Dynamics, 40, 2359-2380.

709 Rayner, N., Parker, D., Horton, E., Folland, C.K., Alexander, L., Rowell, D., Kent, E., Kaplan, A., 2003. Global analyses of sea surface temperature, sea ice, and night marine air temperature since the late nineteenth century. J. Geophys. Res, 108, 4407.

713 Rossby, C.G., 1939. Relation between variations in the intensity of the zonal circulation of the atmosphere and the displacements of the semipermanent centers of action. Journal of Marine Research, 2, 38-55.

715

716

717

718

719 Reconstructing the subsurface ocean decadal variability using surface nudging in a perfect model framework. Climate Dynamics, 44, 315-338.

Sévellec, F., et al., 2009: Nonnormal multidecadal response of the thermohaline circulation induced by optimal surface salinity perturbations. J. Phys. Oceanogr., 39, 852-872.

Sévellec, F., Fedorov, A.V., 2013. The Leading, Interdecadal Eigenmode of the Atlantic Meridional Overturning Circulation in a Realistic Ocean Model. Journal of Climate, 26, 2160-2183.

Sévellec, F., Fedorov, A.V., 2015. Optimal excitation of AMOC decadal variability: Links to the subpolar ocean. Progress in Oceanography, 132, 287-304.

Sévellec, F., Huck, T., 2015. Theoretical investigation of the Atlantic multidecadal oscillation. Journal of Physical Oceanography, published online.

Sévellec, F., Huck, T., Ben Jelloul, M., Vialard, J., 2009. Nonnormal Multidecadal Response of the Thermohaline Circulation Induced by Optimal Surface Salinity Perturbations. J Phys Oceanography, 39, 852-872.

Schlesinger, M.E., Ramankutty, N., 1994. An oscillation in the global climate system of period 65-70 years. Nature, 367, 723-726.

Sicre, M., Jacob, J., Ezat, U., Rousse, S., Kissel, C., Yiou, P., Eiríksson, J., Knudsen, K.L., Jansen, E., Turon, J.-L., 2008. Decadal variability of sea surface temperatures off North Iceland over the last 2000 years. Earth and Planetary Science Letters, 268, 137-142.

Swingedouw, D., Braconnot, P., Delecluse, P., Guilyardi, E., Marti, O., 2007. The impact of global freshwater forcing on the thermohaline circulation: adjustment of North Atlantic convection sites in a CGCM. Climate Dynamics, 28, 291-305.

Swingedouw, D., Mignot, J., Labetoulle, S., Guilyardi, E., Madec, G., 2013. Initialisation and predictability of the AMOC over the last 50 years in a climate model. Climate Dynamics, 40 , 2381-2399.

741 Swingedouw, D., Ortega, P., Mignot, J., Guilyardi, E., Masson-Delmotte, V., Butler, P.G.,

742 Khodri, M., Séférian, R., 2015. Bidecadal North Atlantic ocean circulation variability controlled by timing of volcanic eruptions. Nat. Commun. 6, published online.

te Raa, L., Dijkstra, H., 2002. Instability of the thermohaline ocean circulation on interdecadal timescales. Journal of Physical Oceanography, 32, 138-160.

Timmermann, A., Latif, M., Voss, R., Grötzner, A., 1998. Northern Hemispheric Interdecadal Variability: A Coupled Air-Sea Mode. J Climate, 11, 1906-1931.

Tulloch, R., Marshall, J., 2012. Exploring Mechanisms of Variability and Predictability of Atlantic Meridional Overturning Circulation in Two Coupled Climate Models. J. Climate, 25, 4067-4080.

751 Tulloch, R., Marshall, J., Smith, K.S., 2009. Interpretation of the propagation of surface 752 altimetric observations in terms of planetary waves and geostrophic turbulence. Journal of 
754 Vellinga, M., Wu, P., 2004. Low-Latitude Freshwater Influence on Centennial Variability of 755 the Atlantic Thermohaline Circulation. J Climate, 17, 4498-4511.

756 Venegas, S.A., Mysak, L.A., 2000. Is there a dominant timescale of natural climate 757 variability in the Arctic? Journal of Climate, 13, 3412-3434.

758 Vianna, M.L., Menezes, V.V., 2013. Bidecadal sea level modes in the North and South

759 Atlantic Oceans. Geophysical Research Letters, 40, 5926-5931.

760

761 